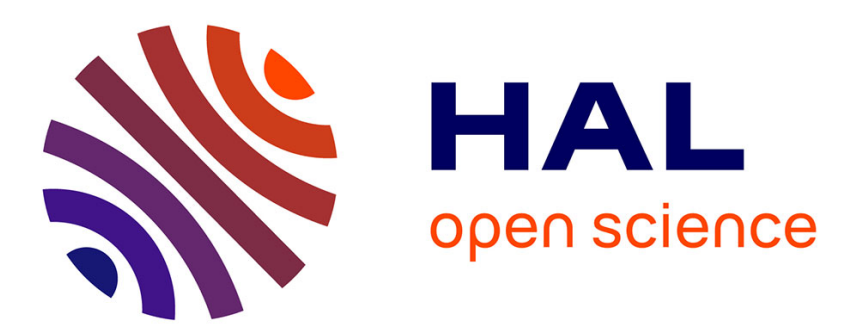

\title{
Estimating the uncertainty of streamgauging techniques using in situ collaborative interlaboratory experiments
}

\author{
J. Le Coz, B. Blanquart, K. Pobanz, Guillaume Dramais, G. Pierrefeu, A.
}

Hauet, A. Despax

\section{- To cite this version:}

J. Le Coz, B. Blanquart, K. Pobanz, Guillaume Dramais, G. Pierrefeu, et al.. Estimating the uncertainty of streamgauging techniques using in situ collaborative interlaboratory experiments. Journal of Hydraulic Engineering, 2016, 142 (7), 43 p. hal-01707833

\section{HAL Id: hal-01707833 \\ https://hal.science/hal-01707833}

Submitted on 13 Feb 2018

HAL is a multi-disciplinary open access archive for the deposit and dissemination of scientific research documents, whether they are published or not. The documents may come from teaching and research institutions in France or abroad, or from public or private research centers.
L'archive ouverte pluridisciplinaire HAL, est destinée au dépôt et à la diffusion de documents scientifiques de niveau recherche, publiés ou non, émanant des établissements d'enseignement et de recherche français ou étrangers, des laboratoires publics ou privés. 
Author-produced version of the article published in Journal of Hydraulic Engineering-ASCE (2016), vol. 142, $n^{\circ} 7$

\title{
Estimating the uncertainty of streamgauging techniques using in situ collaborative interlaboratory experiments
}

\author{
J. Le Coz ${ }^{\mathrm{a}, *}$, B. Blanquart ${ }^{\mathrm{b}}$, K. Pobanz ${ }^{\mathrm{c}}$, G. Dramais ${ }^{\mathrm{d}}$, G. Pierrefeu $^{\mathrm{e}}$, A. Hauet ${ }^{\mathrm{f}}$, \\ A. Despax ${ }^{g}$ \\ ${ }^{a}$ Scientist (PhD), Irstea, UR HHLY, Hydrology-Hydraulics, 5 rue de la Doua CS70077 69626 \\ Villeurbanne cedex, France \\ ${ }^{b}$ Independent expert (PhD), 40 avenue du Général Leclerc, 54600 Villers-lès-Nancy \\ ${ }^{c}$ Engineer, Compagnie Nationale du Rhône (CNR), 4 rue de Chalon-sur-Saône, 69007 Lyon, France \\ ${ }^{d}$ Engineer, Irstea, UR HHLY, Hydrology-Hydraulics, 5 rue de la Doua CS70077 69626 Villeurbanne \\ cedex, France \\ ${ }^{e}$ Expert, Compagnie Nationale du Rhône (CNR), 4 rue de Chalon-sur-Saône, 69007 Lyon, France \\ ${ }^{f}$ Expert (PhD), EDF-DTG, 21 avenue de l'Europe BP41 38040 Grenoble Cedex 09, France \\ ${ }^{g}$ PhD student, Laboratoire d'Etude des Transferts en Hydrologie et Environnement (LTHE), INP \\ Grenoble, Grenoble, France. EDF-DTG, 21 avenue de l'Europe BP41 38040 Grenoble Cedex 09, France
}

\begin{abstract}
While the application of uncertainty propagation methods to hydrometry is still challenging, in situ collaborative interlaboratory experiments are a valuable tool for empirically estimating the uncertainty of streamgauging techniques in given measurement conditions. We propose a simple procedure for organizing such experiments and processing the results according to the authoritative ISO standards related to interlaboratory experiments, which are of common practice in many metrological fields. Beyond the computation and interpretation of the results, some issues are discussed as regards: the estimation of the streamgauging technique bias in the absence of accurate enough discharge references in rivers; the uncertainty of the uncertainty estimates, according to the number of participants and repeated measurements; the criteria related to error sources which are possibly meaningful for categorizing measurement conditions. The interest and limitations of the in situ collaborative interlaboratory experiments are exemplified by an application to the
\end{abstract}

\footnotetext{
${ }^{*}$ Corresponding author (ORCID: 0000-0003-1243-6955). Tel: +33 472208786; fax: +33 478477875.

Email addresses: jerome.lecoz@irstea.fr (J. Le Coz), bertrand.blanquart@gmail.com (B. Blanquart), k.pobanz@cnr.tm.fr (K. Pobanz), guillaume.dramais@irstea.fr (G. Dramais), g.pierrefeu@cnr.tm.fr (G. Pierrefeu), alexandre.hauet@edf.fr (A. Hauet), aurelien.despax@ujf-grenoble.fr (A. Despax)
} 
Author-produced version of the article published in Journal of Hydraulic Engineering-ASCE (2016), vol. 142, $n^{\circ} 7$ The original publication is available at http://ascelibrary.org/doi/abs/10.1061/\%28ASCE\%29HY.1943-7900.0001109

doi : 10.1061/(ASCE)HY.1943-7900.0001109

hydro-acoustic profiler (ADCP) streamgauging technique conducted in 2010 at two different sites downstream of Génissiat hydropower plant in the Rhône river, France. Typically, the expanded uncertainty (with a probability level of 95\%) of the average discharge over 6 successive transects varied from $\pm 5 \%$ at one site with favourable conditions to $\pm 9 \%$ at the other site due to unstable flow conditions.

Keywords: interlaboratory experiments, hydrometry, uncertainty analysis, streamgauging, ADCP

\section{Introduction}

Quantifying the uncertainty associated with discharge measurements in open-channel flows is widely recognised to be of paramount importance for the proper interpretation of hydrological results and for making the relevant decisions. A considerable amount of research has been undertaken to investigate the sources of errors in the diverse streamgauging techniques that are routinely applied by hydrological services around the world (cf. e.g., Pelletier, 1988; McMillan et al., 2012). For instance, sensitivity tests and uncertainty analysis were recently proposed for the velocity-area technique (Le Coz et al., 2012; Cohn et al., 2013), acoustic current Doppler profilers (ADCP) in stationary (Huang, 2012; Lee et al., 2014) or moving-vessel (Gonzalez-Castro and Muste, 2007; Garcia et al., 2012) deployment modes, image sequence processing (Hauet et al., 2008b), etc. While standardised methods for uncertainty analysis in hydrometry are still under development, there are several outstanding difficulties for full-fledged uncertainty analysis. Among them are: i) the discharge of streams is not measured directly, but computed from the uncertain measurements of a number of input quantities, such as point velocities, flow depths, positions, water temperature, angles, etc., and ii) discharge measurements are conducted in situ, often time at sites with complexity in their mean and turbulent flow distribution across the section, leading to errors.

The example of what is happening in measurement areas that are more metrologically advanced helps to clarify what could be adapted for use in hydrometry. Full-fledged uncertainty analysis can be relatively conveniently applied in engineering areas such as 
Author-produced version of the article published in Journal of Hydraulic Engineering-ASCE (2016), vol. 142, $n^{\circ} 7$ The original publication is available at http://ascelibrary.org/doi/abs/10.1061/\%28ASCE\%29HY.1943-7900.0001109

doi : 10.1061/(ASCE)HY.1943-7900.0001109

mechanical, electrical where most of the measurements are easily controlled. For such situations, the Guide to the expression of uncertainty in measurement (GUM) (JCGM, 2008) offers a standardised framework for the uncertainty analysis of measurements, based on the equation of the measurement process (Data Reduction Equation, DRE) and the propagation of the elemental uncertainties, which can be done using a first-order Taylor expansion of the DRE. According to Muste and Bertrand-Krajewski (2012), such a framework must be considered as the reference for developing uncertainty analysis, and its application to hydrometric techniques is feasible. However, quantifying all uncertainty components is not straightforward.

The GUM framework may be summarised as follows: each error source (or 'effect') is corrected through the DRE; each correction is a random variable with mean $\mu$ and variance $\sigma^{2}$ that both must be estimated; typically, $\mu$ is taken equal to zero, except for calibration purpose. Depending on the available information, $\sigma$ is determined using a Type A method (i.e., $\sigma$ is approximated by an experimental standard-deviation $s$ determined from repeated measurements or previous experiments) or a Type B method (i.e., $\sigma$ is determined from the range of the random variable and the assumed probability density function). Standard uncertainties $\sigma$ are generally estimated from experiments (new or previous), hardly ever using other methods such as numerical simulation. Quantifying each uncertainty component is however a daunting task in general. In hydrometry in particular, empirical values based on expert judgement or of unknown origin are usually assigned to important uncertainty components (e.g. many of the tables in ISO 748, 2007). Such difficulty is not related to the quantifying method (Type A or Type B), rather to the complexity to isolate the effect of the uncertainty component under consideration, amongst the other sources of variability.

Interlaboratory experiments are a useful method to estimate uncertainty when a mathematical model of the whole measurement process is not available, or too complex. In essence, interlaboratory experiments consist of measuring the same variable (or measurand) with several participants 'or laboratories' using the same measurement procedure. In the context of streamflow measurements, a 'laboratory' is the combination of one or several operator(s), their equipment and their measurement site. Note that 'laboratory' 
Author-produced version of the article published in Journal of Hydraulic Engineering-ASCE (2016), vol. 142, $n^{\circ} 7$ The original publication is available at http://ascelibrary.org/doi/abs/10.1061/\%28ASCE\%29HY.1943-7900.0001109

doi : 10.1061/(ASCE)HY.1943-7900.0001109

does not mean 'facility' here: in the field of hydrometry all the laboratories must work in the same facility, i.e. stream section, since the single flow that has to be measured by all participants cannot be transferred in time and space. Interlaboratory experiments are guided by several international standards, especially ISO/IEC 17043 (2010) on conformity assessment, ISO 5725-2 (1994) on the uncertainty analysis of measurement techniques and ISO 13528 (2005) on statistical computation procedures.

In metrology, interlaboratory experiments are used for distinct purposes, which cannot be aimed at simultaneously since they imply different, and possibly conflictual constraints on the design of the experiments. They are notably used to confirm the uncertainties obtained by the propagation method, which is required for National Metrology Institutes and most recommended for accredited laboratories to defend their best claimed uncertainty levels. The main applications of interlaboratory experiments are related to three major steps in the life of a measurement technique. First, interlaboratory experiments can be used to establish reference values, which will be further available for uncertainty analysis or other purposes. Second, interlaboratory experiments can be used to investigate the performance of a measurement technique: they are then designed as collaborative studies aiming at identifying the main factors of influence for the given measurement technique and quantifying their effects in terms of uncertainty. Third, interlaboratory experiments can be used to assess the ability of a laboratory to correctly apply the measurement technique: they are commonly used for monitoring the results quality of a laboratory, in line with its accreditation typically. Such proficiency testings are possible only after the measurement technique has been thoroughly investigated and all influence factors were identified; notice that conformity of a laboratory in proficiency interlaboratory experiments is a necessary but not sufficient condition to assure the quality of the results in other conditions (sites, instruments, operators).

The use of interlaboratory experiments (ISO 5725-2, 1994) for conducting the uncertainty analysis of a streamgauging technique is the main motivation for the present methodological paper. The average scatter in the repeated measurements of a participant (repeatability standard deviation) and the scatter in the mean values provided by the dif- 
Author-produced version of the article published in Journal of Hydraulic Engineering-ASCE (2016), vol. 142, $n^{\circ} 7$ The original publication is available at http://ascelibrary.org/doi/abs/10.1061/\%28ASCE\%29HY.1943-7900.0001109

doi : 10.1061/(ASCE)HY.1943-7900.0001109

ferent participants (interlaboratory standard deviation) can be analysed to evaluate the uncertainty of the measurement technique, in the conditions of the experiments. One must be aware that interlaboratory experiments provide an estimation of the repeatability and reproducibility of a measurement technique, not of the uncertainty of a measurement result (cf. ISO 5725-1, 1994). Such an estimate contains the average uncertainty associated with the measuring technique, in the given conditions of the experiment. The resulting uncertainty does not include the non-covered sources of errors, nor the systematic errors common to all participants, i.e. the bias of the measurement technique. This bias can be estimated by comparison with a reference measurement with an uncertainty which is known to be smaller, at least 3 to 10 times smaller typically (cf. e.g. ISO 13528, 2005), than that of the measurement technique under investigation.

The recent ISO 21748 (2010) standard represents an important advance for bridging the apparent gap between the uncertainty propagation framework of the GUM (JCGM, 2008) and the empirical uncertainties established from interlaboratory experiments (ISO 57252, 1994). Indeed, while referring explicitly to the GUM as the reference framework for uncertainty analysis, the ISO 21748 (2010) standard provides guidelines for assessing uncertainty from interlaboratory experiment results and for comparing such results with the measurement uncertainty obtained with the uncertainty propagation at the level of elemental errors. This approach is now recommended by accreditation bodies, at the international level (e.g. COFRAC, 2015). ISO 21748 (2010) is actually based on the following uncertainty propagation equation, which allows for uncertainty budgets in compliance with the GUM:

$$
u^{2}(y)=u^{2}(\hat{\delta})+s_{L}^{2}+\sum c_{i}^{2} u^{2}\left(x_{i}\right)+s_{r}^{2}
$$

where $u(y)$ is the uncertainty associated with the measurement result $(y), u(\hat{\delta})$ is the uncertainty associated with the estimator of the measurement technique bias $(\hat{\delta}), s_{L}$ is the interlaboratory standard deviation, $u\left(x_{i}\right)$ with sensitivity coefficients $c_{i}$ are the uncertainties related to the effects not covered in the experiments (input quantities $x_{i}$ ), and $s_{r}$ is the intra-laboratory standard deviation (repeatability). In order not to double count errors or 
Author-produced version of the article published in Journal of Hydraulic Engineering-ASCE (2016), vol. 142, $n^{\circ} 7$ The original publication is available at http://ascelibrary.org/doi/abs/10.1061/\%28ASCE\%29HY.1943-7900.0001109

doi : 10.1061/(ASCE)HY.1943-7900.0001109

miss some of them in applying Eq. 1, it is important to associate every elemental error sources with covered or not covered effects.

The objective of this article is to introduce a method developed according to the aforementioned standard documents for empirically quantifying the uncertainty of streamgauging techniques from in situ collaborative interlaboratory experiments. Results obtained in interlaboratory experiments with ADCPs, hand-held surface velocity radars (SVR) and current-meters organised by the authors at regional and national scales (Le Coz et al., 2009; Dramais et al., 2011; Pobanz et al., 2011; Hauet et al., 2012; Dramais et al., 2013; Despax et al., 2014; Pobanz et al., 2015) and from similar field campaigns (Iredale, 2006; Everard, 2007, 2009; Terek et al., 2013; Folk, 2014), allow to provide guidelines for conducting such experiments and reporting the results. Specifically, the methodology is exemplified with the hydro-acoustic profilers (ADCP) interlaboratory experiments conducted in 2010 at two different sites downstream of Génissiat hydropower plant in the Rhône river, France. The analysis of these measurements provided interesting results regarding two major issues: 1) the difficulty to quantify the streamgauging technique bias against a reference in field conditions and 2) the definition of meaningful metrics or indicators of the error sources related to the measurement conditions of ADCP gauging data.

\section{Methods}

\section{Requirements for organizing hydrometric interlaboratory experiments}

It is very useful to organise a hydrometric interlaboratory experiment according to a priority objective, ideally a single objective. The most commonly expressed objectives are: 1) test the proficiency of participants and instruments (proficiency testings) and 2) investigate the uncertainty of the streamgauging technique (collaborative studies). As already discussed, both objectives cannot be aimed at simultaneously, and only the latter objective is addressed in this paper.

The requirements and assumptions of collaborative interlaboratory experiments may be summarised as follows. First, even if not identical, all participant skills, instruments, 
Author-produced version of the article published in Journal of Hydraulic Engineering-ASCE (2016), vol. 142, $n^{\circ} 7$

The original publication is available at http://ascelibrary.org/doi/abs/10.1061/\%28ASCE\%29HY.1943-7900.0001109

doi : 10.1061/(ASCE)HY.1943-7900.0001109

procedures, cross-sections, etc., are assumed to be equivalent and representative of the same measurement technique in the same conditions. Operators are required to be trained, proficient and experienced in the operation of the hydrometric instruments. Still, obvious malfunction of the instrument or inappropriate procedures are easily detected during such experiments.

All participants should follow the same, or similar, procedures with a clear distinction between fixed and free parameters. All measurements should be conducted in a homogeneous site, i.e. at identical or close positions, with similar conditions. Discharge measurements should be ideally simultaneous, and repeated at least twice for assessing the repeatability. A similar number of valid measurements for each instrument is preferred. Participants must strictly observe the imposed schedule and protocols of the experiments. In particular, the participants must not change their measuring locations in the stream, the instruments or settings during the experiments.

Discharge and hydraulic conditions should be steady, which is sometimes problematic in natural conditions. The unavoidable variability of discharge during the experiments should be lower than the streamgauging uncertainty that is to be investigated. The amplitude of water level and velocity fluctuations should be monitored using alternative measurement. If available, numerical simulations of the flow conditions during the experiments provide a useful information on the water stage and velocity stability. Of course, assessing the flow stability based on the results of the interlaboratory experiments is not acceptable since it would be circular inference. Flow disturbance and interferences by operators and instruments should be minimised by all possible means. Availability of discharge to be used as a reference is not absolutely necessary but it is always useful, to discard outliers and to investigate the bias of the studied streamgauging technique.

Irrespective of the number of participants and the duration of the experiments, the logistics and safety measures are always important. The main practical steps are summarised in Tab. 1. 


\section{Standardised sources and assumptions}

The data processing follows the guidelines provided by the following international standards:

- ISO 5725-2 (1994): quantification of the performance of a measurement technique in terms of repeatability and reproducibility;

- ISO 21748 (2010): translation of previous results in terms of measurement uncertainty;

- ISO 13528 (2005) or ISO 21748 (2010): determination of the uncertainty associated with the average flow rate calculated from all participants;

- ISO 5725-1 (1994): determination of the uncertainty associated with the repeatability and reproducibility estimates.

Several assumptions are necessary for the implementation of these standards. First, only the error sources covered by the tests are considered as included in the experimental results. Also, it is assumed that the results are uncorrelated and that the measurement errors follow a Gaussian (or at least unimodal) distribution. Last, in the ISO 5725-2 (1994) standard, it is assumed that the repeatability is the same for all participants, and to a lesser extent, that the number of runs is the same for all participants.

\section{Model of errors}

Consider $Q_{i, k}$, the $k^{\text {th }}$ instantaneous discharge measurement performed by the $i^{\text {th }}$ laboratory during a steady flow:

$$
Q_{i, k}=Q_{\text {true }}+\delta+B_{i}+\epsilon_{i, k}
$$

with $Q_{\text {true }}$ the true discharge value (unknown), $\delta$ the bias associated with the measurement technique (the same for all participants involved in the interlaboratory experiment), and $B_{i}$ and $\epsilon_{i, k}$ the systematic (bias) and random errors related to the $i^{\text {th }}$ laboratory and its $k^{\text {th }}$ measurement. 
Author-produced version of the article published in Journal of Hydraulic Engineering-ASCE (2016), vol. 142, $n^{\circ} 7$ The original publication is available at http://ascelibrary.org/doi/abs/10.1061/\%28ASCE\%29HY.1943-7900.0001109

doi : 10.1061/(ASCE)HY.1943-7900.0001109

During an interlaboratory experiment, the reference discharge value is built as $Q_{\text {mean }}=$ $Q_{\text {true }}+\delta$, the average of all discharge values of the experiment, i.e. of all the measurements obtained by all the $p$ laboratories involved in the experiment.

The measurement errors in the $k^{\text {th }}$ discharge $Q_{i, k}$ measured by the $i^{\text {th }}$ laboratory can be modelled as follows:

$$
Q_{i, k}=Q_{\text {mean }}+B_{i}+\epsilon_{i, k} \quad \text { with } \quad B_{i} \sim \mathcal{N}\left(0, \sigma_{L}\right) \quad \text { and } \quad \epsilon_{i, k} \sim \mathcal{N}\left(0, \sigma_{r}\right)
$$

The random error, $\epsilon_{i, k}$, is assumed to follow a Gaussian distribution of mean zero and standard deviation $\sigma_{r}$. With the needed corrections being applied to results, the systematic error, $B_{i}$, is assumed to follow a Gaussian distribution of mean zero and standard deviation $\sigma_{L}$. This assumption requires that instruments are calibrated and corrected at the maximum extent possible.

\section{Processing of the comparison results}

The processing of results obtained from interlaboratory experiments is detailed in the ISO 5725-2 (1994) standard. After collecting and formatting the data, the reviewing of the individual measurement values is carried out. The ISO 5725-2 (1994) standard recommends that $h$ and $k$ Mandel criteria be calculated and plotted, in order to visually check the homogeneity and consistency of the measurements. These criteria intend to quickly identify participants that would present a different behaviour, in terms of accuracy ( $h$ criteria) or in terms of dispersion ( $k$ criteria). Detecting one or several participants with a markedly different behaviour compared to others may lead to statistical tests for outlier detection, with the optional implementation of Cochran and Grubbs tests. Such tests may be used to justify discarding data from the pool, in order to get a homogeneous sample that is representative of the performance of instruments and participants with similar accuracy and dispersion. The reader is referred to the ISO 5725-2 (1994) standard for precise details on how to implement $h$ and $k$ Mandel criteria, as well as Cochran and Grubbs tests.

ISO 5725-2 (1994) standard provides procedures for computing the variance estimators, $s_{r}, s_{L}$ and $s_{R}$ in Eq. 1, using the results of the interlaboratory experiments. Such estima- 
tors respectively provide the best estimates of the true repeatability, interlaboratory and reproducibility standard deviations, $\sigma_{r}, \sigma_{L}$ and $\sigma_{R}$, which remain unknown.

The repeatability $s_{r}$ is computed from the experimental standard deviations, $s_{i}$, of the $n_{i}$ repeated discharge measurement, $Q_{i, k}$, provided by each participant $i$, as follows:

$$
s_{r}^{2}=\frac{\sum_{i=1}^{p}\left(n_{i}-1\right) s_{i}^{2}}{\sum_{i=1}^{p}\left(n_{i}-1\right)} \quad \text { with } \quad s_{i}^{2}=\frac{1}{n_{i}-1} \sum_{k=1}^{n_{i}}\left(Q_{i, k}-\bar{Q}_{i}\right)^{2}
$$

In case $n_{i}=2$ only, the standard deviation is estimated to be $s_{i}=\left|Q_{i, 2}-Q_{i, 1}\right| / \sqrt{2}$.

The interlaboratory standard deviation, $s_{L}$, is estimated using the following equation:

$s_{L}^{2}=\frac{s_{d}^{2}-s_{r}^{2}}{\bar{n}} \quad$ with $s_{d}^{2}=\frac{1}{p-1} \sum_{i=1}^{p} n_{i}\left(\bar{Q}_{i}-Q_{\text {mean }}\right)^{2} \quad$ and $\bar{n}=\frac{1}{p-1}\left[\sum_{i=1}^{p} n_{i}-\frac{\sum_{i=1}^{p} n_{i}^{2}}{\sum_{i=1}^{p} n_{i}}\right]$

In case that $s_{d}<s_{r}, s_{L}$ is taken equal to zero.

Then, the reproducibility standard deviation, $s_{R}$, is simply taken to be equal to:

$$
s_{R}^{2}=s_{r}^{2}+s_{L}^{2}
$$

ISO 21748 (2010) is finally invoked to assimilate $s_{R}$ and $u(Q)$, the combined standard uncertainty of the discharge. Assuming that all the non-negligible error sources were covered through the interlaboratory experiments, then the $c_{i} u\left(x_{i}\right)$ terms can be neglected and Eq. 1 from ISO 21748 (2010) leads to the following expression of the expanded discharge uncertainty:

$$
U(Q)=k \sqrt{s_{R}^{2}+u^{2}(\hat{\delta})}=k \sqrt{s_{r}^{2}+s_{L}^{2}+u^{2}(\hat{\delta})}
$$

with $k$ the coverage factor used to expand the uncertainty within a given probability level. The Hydrometric Uncertainty Guidance (HUG) (ISO/TS 25377, 2007) recommends that $k=2$ should be chosen because the corresponding $95 \%$ probability level is considered to 
Author-produced version of the article published in Journal of Hydraulic Engineering-ASCE (2016), vol. 142, $n^{\circ} 7$ The original publication is available at http://ascelibrary.org/doi/abs/10.1061/\%28ASCE\%29HY.1943-7900.0001109 doi : 10.1061/(ASCE)HY.1943-7900.0001109

be the most appropriate for many testing and calibration applications. In this whole document, uncertainty components $u(X)$ are relative standard uncertainties (in \% of measurand $X)$, while terms $U(X)$ denote the relative expanded uncertainties $(U(X)=k u(X), k=2$, $95 \%$ probability level). Also remind that the standard uncertainty, $u(\hat{\delta})$, is related to the estimation of the streamgauging technique bias, $\hat{\delta}$, which is discussed in the next section.

\section{Estimation of the streamgauging technique bias}

Estimation of the discharge measurement technique bias, $\hat{\delta}$, and its uncertainty, $u(\hat{\delta})$, is not a trivial task when no reference value is available, which is almost always the case for stream discharges in natural conditions. Ideally, a reference value should be a reproducible value with a widely accepted, small uncertainty, and related to the most fundamental international standards. The most accurate determination of a discharge (in $\mathrm{m}^{3} / \mathrm{s}$ ) would be the measurement of the water volume difference (in $\mathrm{m}^{3}$ ) over a given duration (in seconds), or the measurement of its weight and density. Such an accurate reference measurement is feasible in small scale laboratory conditions, but obviously not in natural streams.

Alternatively, a GUM-based approach could be followed in order to propagate the elemental uncertainties related to the measurement technique bias, based on available laboratory calibrations traceable to metrological standards. For instance, the bias in measuring the water velocity and the bottom-track velocity by current-meters and acoustic profilers (ADCP) can be assessed from testing in tow-tank facilities. Unfortunately, this approach cannot be completed for all the systematic errors of discharge measurements in natural conditions, because of the large number of elemental error sources and the complexity of those related to the environment and the operator effects.

In best cases, it is possible to compare the average result, $Q_{\text {mean }}$, of all the participants of an interlaboratory experiment with some reference discharge value, $Q_{\text {ref }}$, given by another system with a quantified and smaller uncertainty, $u\left(Q_{\text {ref }}\right)$. Then, the expressions for $\hat{\delta}$ and $u(\hat{\delta})$ simply write:

$$
\begin{gathered}
\hat{\delta}=Q_{\text {mean }}-Q_{\text {ref }} \\
u^{2}(\hat{\delta})=u^{2}\left(Q_{\text {mean }}\right)+u^{2}\left(Q_{\text {ref }}\right)
\end{gathered}
$$


The latter equation (Eq. 8) assumes that the measurement errors of the tested streamgauging technique and the reference are statistically independent. Note that Eq. 8 for $u(\hat{\delta})$ is preferred over the estimation proposed in Section 6.3.3.1 of ISO 5725-1 (1994) where the uncertainty of the reference discharge is neglected, which is not valid in hydrometric applications.

According to the Eq. 15 of ISO 21748 (2010) standard, the uncertainty in $Q_{\text {mean }}$ can be evaluated considering the number, $n$, of measurements repeated by each of the $p$ participants during the experiment, which leads to the following equation:

$$
u(\hat{\delta})=\sqrt{\frac{s_{r}^{2}}{n p}+\frac{s_{L}^{2}}{p}+u^{2}\left(Q_{\mathrm{ref}}\right)}
$$

Note. Even using a reliable and precise reference measuring system, many interlaboratory experiments are necessary to assess $\hat{\delta}, u(\hat{\delta})$ and their possible dependencies on major influence factors. Usually, a major practical issue is to assess $u\left(Q_{\text {ref }}\right)$, which must be estimated independently of the interlaboratory experiments, of course.

\section{Uncertainty of the uncertainty estimates}

Due to the limited number, $p$ and $n$, of participants and repeated measurements, respectively, there is some uncertainty in the results of the interlaboratory experiments due to the sampling variability. The ISO 5725-1 (1994) standard introduces the following approximate equations for assessing the relative uncertainty of $s_{r}$ and $s_{R}$ estimates with a probability level of $95 \%$ :

$$
\begin{gathered}
A_{r}=1.96 \sqrt{\frac{1}{2 p(n-1)}} \\
A_{R}=1.96 \sqrt{\frac{p\left[1+n\left(\gamma^{2}-1\right)\right]^{2}+(n-1)(p-1)}{2 \gamma^{4} n^{2}(p-1) p}}
\end{gathered}
$$

where $\gamma=\sigma_{R} / \sigma_{r} \approx s_{R} / s_{r}$.

Neglecting the streamgauging technique bias, $u(\hat{\delta})$, in Eq. 7, means that the 'true' uncertainty, $2 \sigma_{R}$, is estimated by $U(Q)=2 s_{R}$, i.e. twice the reproducibility standard deviation. 
Author-produced version of the article published in Journal of Hydraulic Engineering-ASCE (2016), vol. 142, $n^{\circ} 7$ The original publication is available at http://ascelibrary.org/doi/abs/10.1061/\%28ASCE\%29HY.1943-7900.0001109

Re-arranging Eq. 7 of ISO 5725-1 (1994), which states that $\left.\left(s_{R}-\sigma_{R}\right) / \sigma_{R} \in\right]-A_{R} ; A_{R}[$, leads to the following uncertainty interval around the 'true' discharge uncertainty:

$$
\frac{U(Q)}{1+A_{R}}<2 \sigma_{R}<\frac{U(Q)}{1-A_{R}}
$$

Typical results obtained using Eq. 13 are plotted in Fig. 1. They are helpful for assessing the relative advantage of increasing the number of repeated discharge measurements, $n$ (Fig. 1a) or the number of laboratories, $p$ (Fig. 1b) to improve the accuracy of the reproducibility estimate, hence of the uncertainty estimate, $U(Q)$. Typical values of $n, p$ and of the reproducibility-to-repeatability ratio $\left(\gamma=\sigma_{R} / \sigma_{r}\right)$ are considered. Both figures illustrate that the uncertainty intervals around the uncertainty estimate are asymmetrical, quite wide (70\% to $150 \%$ of $U(Q)$ typically) and highly sensitive to the value of $\gamma$. When $\gamma>1$, i.e. when the interlaboratory standard-deviation, $s_{L}$, is not negligible compared to the repeatability standard-deviation, $s_{r}$, the uncertainty of the uncertainty significantly increases.

It also appears that increasing the number of participants is more efficient than increasing the number of repeated measurements to improve the uncertainty results. For typical values of $\gamma(1.5)$, there is no significant advantage in repeating the measurements more than 4 or 6 times, while there is significant advantage in gathering up to 10 participants, or even more. Such results suggest that a large number of participants is preferable for studying 'slow' streamgauging techniques (e.g. current-meter), as well as 'fast' streamgauging techniques (e.g. ADCP, tracer dilution). However it remains advisable to repeat the measurements as many times as feasible to decrease the uncertainty of the uncertainty results. When interlaboratory experiments are conducted with current-meters on wading rods in small natural streams, it is usually difficult to repeat the measurements more than 2 or 3 times with steady flow conditions. The limited number of repeated discharge measurements, $n$, then leads to uncertainties in the uncertainty estimates that can be much larger than differences obtained for contrasted site conditions (Despax et al., 2014). 


\section{Averaged discharge measurements}

In some streamgauging techniques, each discharge measurement, $Q^{N, P}$, is actually established from the average of $N$ repeated measurements for each of $P$ instruments. For example, a gauging conducted with an ADCP is usually the mean of $N=4-6$ successive transects. Usually, $P=1$, but for specific applications when a minimal uncertainty is required, several ADCP may be used simultaneously and their results may be averaged altogether.

Using interlaboratory experiments data for ADCP gaugings, it is possible to compute the uncertainty on $Q^{N, P}$ 'directly', by applying the interlaboratory procedure to discharge data established as in the field, i.e. as the average of $N \times P$ primary discharge measurements from $N$ successive transects and $P$ ADCP. However, computing $s_{r}$ and $s_{R}$ from discharge data established from each ADCP transect is more convenient because individual discharges do not have to be clustered by 4 or 6 . The uncertainty estimation is also expected to be more accurate, since Eq. 11 and Eq. 12 show that $A_{r}$ and $A_{R}$ are smaller when $n$ and $p$ are greater. The ISO 21748 (2010) standard can again be followed to establish the following formula to extend the uncertainty results obtained from elementary discharges (1 transect, $1 \mathrm{ADCP})$ to the uncertainty in discharge values determined as the average of $N$ successive measurements done by each of $P$ instruments:

$$
U\left(Q^{N, P}\right)=k \sqrt{\frac{s_{r}^{2}}{N P}+\frac{s_{L}^{2}}{P}+u^{2}(\hat{\delta})}
$$

In recurrent cases when there is a significant directional bias in the ADCP measurements, i.e. between transects conducted in opposite directions, it would be better to compute $s_{r}$ and $s_{R}$ from discharge averaged over a pair of opposite transects. This would avoid overestimating the repeatability variance since ADCP gaugings are usually the average of a number of transect pairs. 
Author-produced version of the article published in Journal of Hydraulic Engineering-ASCE (2016), vol. 142, $n^{\circ} 7$

The original publication is available at http://ascelibrary.org/doi/abs/10.1061/\%28ASCE\%29HY.1943-7900.0001109

doi : 10.1061/(ASCE)HY.1943-7900.0001109

\section{Application to vessel-mounted ADCP interlaboratory experiments (Génissiat, 2010)}

Field procedure

On 13-14 October 2010 the Groupe Doppler Hydrométrie (Le Coz et al., 2007), a Frenchspeaking community of hydrometry technologists, organised ADCP interlaboratory experiments in the Rhône River downstream of Génissiat hydropower plant, South-East France. The experiments involved 6 types of ADCP from two manufacturers (Teledyne RDI and Sontek), with operating frequencies ranging from 600 to $3000 \mathrm{kHz}$ (cf. Tab. 2). For the sake of this experiment, the 26 devices that were simultaneously deployed were assumed to have equivalent performances and the discharge data from each participant were assumed to be representative of the same ADCP streamgauging technique. To that end, the main deployment and configuration parameters were imposed to be identical or similar for all participants, who were all trained and experienced ADCP users.

Discharge measurements were simultaneously performed by two groups of power boats, with 2 ADCPs with different emitting frequencies mounted on each boat (cf. Fig. 2). Six boats (12 ADCPs) were deployed throughout the river reach located just downstream of the Génissiat hydropower plant, in deep and complex cross-sections (GE site, cf. Fig. 3a). Seven boats (14 ADCPs) were deployed just upstream of the Pyrimont bridge, along a straight and uniform reach located roughly $3.5 \mathrm{~km}$ downstream of the hydropower plant (PY site, cf. Fig. 3b). Water inputs or losses between both sites were negligible. Within each site, different cross-sections offered similar conditions for every participants in the group.

During the two days, 6 time intervals with steady discharge released from the hydropower plant were made available for 6 interlaboratory experiments (cf. Fig. 4, Tab. 3 and Tab. 4). The corresponding average discharges determined from all ADCP measurements were $224 \mathrm{~m}^{3} / \mathrm{s}, 335 \mathrm{~m}^{3} / \mathrm{s}, 436 \mathrm{~m}^{3} / \mathrm{s}, 120 \mathrm{~m}^{3} / \mathrm{s}, 230 \mathrm{~m}^{3} / \mathrm{s}$, and $335 \mathrm{~m}^{3} / \mathrm{s}$, with maximum flow velocity up to $2.5 \mathrm{~m} / \mathrm{s}$. Typically, each interlaboratory experiment lasted for 1 hour with 28 and 18 valid transects on average for each ADCP at sites GE and PY, 
respectively.

In addition to providing steady discharge during the experiments, the hydropower plant was also useful by offering a well-controlled method for discharge measurements $\left(Q_{\text {ref }}\right)$ based on an ultrasonic transit-time system installed in the dam conduits. This acoustic system was calibrated independently of the ADCP measurements, according to the IEC 60041 (1991) international standard and to the OWICS method (Optimal Weighted Integration for Circular Sections), which accounts for the actual positions of the acoustic sensors within the circular conduits (Voser and Staubli, 1998). According to the Appendix J of IEC 60041 (1991), the order of magnitude of the discharge uncertainty is accepted to range from $\pm 1 \%$ to $\pm 2 \%$, though this estimate is based on an analogy with similar systems and was not verified against international standard values. Voser and Staubli (1998) showed that the OWICS method kept the integration error lower than $\pm 1 \%$. Therefore, $U\left(Q_{\text {ref }}\right)= \pm 2 \%$ (i.e., $u\left(Q_{\text {ref }}\right)=1 \%$ ) will be retained as a reasonable assumption in further computations.

\section{Results of the interlaboratory experiments}

Fig. 5 shows the typical results derived from experiments conducted in steady discharge conditions: each participant provided the mean and standard-deviation of their successive valid transects which could be compared to the average discharge of all ADCPs at their site (either GE or PY), and to the average discharge measured by the transit-time system in dam conduits, taken as a discharge reference.

At both sites GE and PY, the standardised method for processing data was implemented to empirically determine the uncertainty related to the ADCP streamgauging technique when applied in the measuring conditions of the experiments. For each interlaboratory experiment and each site, the repeatability $\left(s_{r}\right)$ and interlaboratory $\left(s_{L}\right)$ experimental standard deviations, as well as bias and uncertainty estimates, were computed according to the equations introduced in the previous sections. The results of the 6 successive interlaboratory experiments are presented in Tab. 3 (PY site) and in Tab. 4 (GE site). For a given site, differences in the obtained uncertainty estimates from different 
Author-produced version of the article published in Journal of Hydraulic Engineering-ASCE (2016), vol. 142, $n^{\circ} 7$ The original publication is available at http://ascelibrary.org/doi/abs/10.1061/\%28ASCE\%29HY.1943-7900.0001109

doi : 10.1061/(ASCE)HY.1943-7900.0001109

experiments with different discharges from $120 \mathrm{~m}^{3} / \mathrm{s}$ to $440 \mathrm{~m}^{3} / \mathrm{s}$ were actually found to be negligible: the reproducibility standard deviations, $s_{R}$, shown in Tab. 3 and in Tab. 4 for the six experiments fluctuate within the uncertainty bounds given by Eq. 13. This confirms the usual assumption that gaugings do not show heteroscedasticity according to the discharge: their errors appear to be proportional to the discharge, i.e. constant when expressed in percent of the discharge.

The empirical estimates of the ADCP bias, $\hat{\delta}$ (Eq. 8 ), range from $-1.7 \%$ to $+2.6 \%$ with a slightly greater average at PY site $(\hat{\delta}=+1.6 \%)$ than at GE site $(\hat{\delta}=+0.7 \%)$. However, such bias estimates are not significant due to their own uncertainties. Considering that $u\left(Q_{\text {mean }}\right)$ was found to be roughly $1 \%$ on average and that $u\left(Q_{\text {ref }}\right)$ was also estimated to be $1 \%$, the bias uncertainty, using Eq. 10 leads to $u(\hat{\delta})=1.2 \%$ and $1.6 \%$ for PY and GE sites, respectively.

In parallel to that empirical assessment of the bias of the ADCP streamgauging technique, a sensitivity analysis was applied to different fixed parameters involved in discharge extrapolation in the top, bottom and near-edge unmeasured areas of the cross-section. Such parameters were the sensor immersion depth, the distances from the edges, the assumed shape of the near-edge areas and the assumed type of vertical velocity profile. The dominant error source was found to be the discharge extrapolation in the top and bottom layers. Since the same option was imposed to all participants, i.e. a constant profile in the top layer and a 1/6 power profile in the bottom layer, such parameters certainly induced systematic errors in the average discharge measurements at each site. The sensitivity tests indicated that, in the conditions of the experiments, the magnitude of the errors related to the extrapolation of unmeasured discharges was $\pm 2.5 \%$ on average, with no clear positive or negative bias, which is consistent with the empirical estimates of the bias and of its uncertainty.

For the subsequent uncertainty analysis, a bias value of $\hat{\delta}=0$ (uncorrected results) was assumed and the uncertainty in the bias estimate was estimated to be $u(\hat{\delta})=1.25 \%$, i.e. $U(\hat{\delta})= \pm 2.5 \%$ with a probability level of $95 \%$. The accuracy of the transit-time system was actually too low to quantify the ADCP technique bias. This illustrates the difficulty 
Author-produced version of the article published in Journal of Hydraulic Engineering-ASCE (2016), vol. 142, $n^{\circ} 7$ The original publication is available at http://ascelibrary.org/doi/abs/10.1061/\%28ASCE\%29HY.1943-7900.0001109

doi : 10.1061/(ASCE)HY.1943-7900.0001109

to estimate the streamgauging technique bias experimentally in such a large river, even when the best possible discharge reference is available.

\section{Discussion of the uncertainty results}

Equation 14 was applied to the experimental values for $s_{r}, s_{L}$ and $u(\hat{\delta})=1.25 \%$ to compute the uncertainty of discharge measurements established from 1 ADCP and the average of 1, 4 and 6 successive transects. The difference between sites with favourable (PY) and adverse (GE) measurement conditions was clearly quantified, since the uncertainty at PY site (cf. Tab. 3) is roughly half of the uncertainty at GE site (cf. Tab. 4). The average value obtained for $U\left(Q^{6,1}\right)$ at PY site, $\pm 5.1 \%$, is consistent with the commonly accepted uncertainty value for an ADCP streamgauging conducted in adequate conditions. In contrast, $U\left(Q^{6,1}\right)= \pm 9.3 \%$ at GE site corresponds to a fair quality of an ADCP streamgauging. Note that all the different makes and models of ADCP involved in the experiments were assumed to be equivalent and representative of the same single streamgauging technique. While this assumption seems to be reasonable, it may be interesting to design specific experiments for investigating the relative performances of different instrument types.

The interest of averaging at least four successive transects to reduce the uncertainty is clearly highlighted in the $U\left(Q^{N, P}\right)$ results presented in Tab. 3, Tab. 4 and Fig. 6. Also it can be observed that for more than 6 transects, the uncertainty is virtually constant, while the simultaneous use of 2 or even 4 independent ADCP significantly reduces the uncertainty of the obtained average discharge result. Indeed, repeating transects allows to reduce the repeatability uncertainty, while using several instruments allows to reduce both repeatability and interlaboratory uncertainties (cf. Eq. 14). Based on these and previous observations, the French best practices still recommend to repeat at least 6 valid ADCP transects with the same number of transects in each direction.

While the number of transects is an easy rule of thumb for practitioners, Oberg and Mueller (2012) suggested that the total duration of the ADCP measurements, i.e. the exposure time, was actually a more meaningful parameter as to average turbulent fluctuations and other sources of random errors. Their experimental findings led to the recommenda- 
Author-produced version of the article published in Journal of Hydraulic Engineering-ASCE (2016), vol. 142, $n^{\circ} 7$ The original publication is available at http://ascelibrary.org/doi/abs/10.1061/\%28ASCE\%29HY.1943-7900.0001109

doi : 10.1061/(ASCE)HY.1943-7900.0001109

tion of a minimal exposure time of 720 s. If one considers that an ADCP crossing of the Rhône river lasted for roughly $90 \mathrm{~s}$ in our experiments, $720 \mathrm{~s}$ are equivalent to 8 transects, which is quite consistent with our findings. However, the exposure time should arguably be scaled with the size of the flow to be gauged, turbulence level and other potential site characteristics.

It is important to remind that the uncertainty results obtained from interlaboratory experiments also are uncertain, due to the limitations of the experiments. The assumptions of a steady discharge measured by equivalent participants in equivalent conditions are never fully true in the non-ideal conditions of the field. The related errors in the uncertainty estimates should be minimized as was intended in Génissiat 2010 interlaboratory experiments. As discussed previously, the expanded uncertainty, $A_{R}$, of the reproducibility estimate, $s_{R}$, due to the limited number of participants and repeated measurements can be estimated using Eq. 12. In our example, $A_{R}$ is $\sim 20 \%$ for both sites (cf. Tab. 3 and Tab. 4), which corresponds to an expanded uncertainty bounds of roughly $85 \%$ and $125 \%$ of $U(Q)$ (cf. Eq. 13), the technique bias uncertainty being ignored. This confirms that the difference in uncertainty results at both sites GE and PY can be regarded as significant: typically, $U\left(Q^{6,1}\right)= \pm 9.3 \%$ lays in $[7.7 \% ; 11.8 \%]$ at GE site whereas $U\left(Q^{6,1}\right)= \pm 5.1 \%$ lays in $[4.3 \% ; 6.3 \%]$ at PY site.

Also it is worth mentioning that the ADCP-related bias, $u(\hat{\delta})=1.25 \%$, forces the asymptotical uncertainty value to be no less than $\pm 2.5 \%$ even if an infinity of transects are produced by an infinity of ADCPs. Therefore, for large values of $N$ and $P$, the uncertainty analysis becomes highly sensitive to the estimation of $u(\hat{\delta})$, requiring further investigations. Estimation of the bias of a streamgauging technique such as the ADCP is difficult, if not impossible, without considering a reference discharge technique with uncertainties that are lower than that of the studied technique by a factor 3 or 10, typically. Since such an accurate and traceable discharge reference is usually lacking in natural streams, both discharge calibration and propagation of standard uncertainties cannot be achieved strictly. Sensitivity tests on the main parameters related to systematic errors can help investigate the dominant sources of the bias. 
Author-produced version of the article published in Journal of Hydraulic Engineering-ASCE (2016), vol. 142, $n^{\circ} 7$ The original publication is available at http://ascelibrary.org/doi/abs/10.1061/\%28ASCE\%29HY.1943-7900.0001109

doi : 10.1061/(ASCE)HY.1943-7900.0001109

\section{Discussion on the meaningful characteristics of measurement conditions}

As already mentioned, the uncertainty of a streamgauging technique estimated with interlaboratory experiments is valid only for the conditions of the experiments. The Génissiat 2010 results for ADCPs confirmed that the uncertainty of measured discharges primarily depend on the flow and site conditions, which was expected from the common experience and guidance in hydrometry, whatever the streamgauging technique. As such, results from interlaboratory experiments are of high interest for practitioners because they include the site-specific effects that are difficult to account for in uncertainty propagation methods. Nevertheless, measured discharges are also prone to other sources of error such as those related to the instrumentation, operator, field procedure or postprocessing, including the number of averaged ADCP transects in a discharge result, typically.

Generalizing the uncertainty results obtained from a given interlaboratory experiment to other situations would require to define metrics for characterizing the site and measurement conditions. Such metrics should be related to error sources identified in the measurement process, according to the specific streamgauging technique under consideration: for instance, a fishway may be a very good site for tracer dilution while it is usually not for velocity-area or ADCP. Unfortunately, translating error sources into simple field metrics is not a straightforward task.

Typically, interpreting the causes of the higher uncertainty at GE site compared to PY site as observed in the Génissiat 2010 results was not easy. After checking the deployment, instruments and raw data, it soon appeared clearly that the difference was due to the poor or good site conditions, as also expected from the common expert judgement on the two sites. First, we focussed our analysis on the more complex channel geometry and timeaveraged flow structure at GE site, but we were not able to identify a cause for the greater interlaboratory variability in the geometry measurements, bottom-tracking and discharge extrapolation in the top/bottom layers. Later on, we realised that the flow field was actually much more unstable at GE site than at PY site, with marked secondary currents and intermittent macroturbulent structures as illustrated in Fig. 7. This was attributed to the incomplete establishment of a uniform, turbulent open-channel flow downstream of 
Author-produced version of the article published in Journal of Hydraulic Engineering-ASCE (2016), vol. 142, $n^{\circ} 7$ The original publication is available at http://ascelibrary.org/doi/abs/10.1061/\%28ASCE\%29HY.1943-7900.0001109

doi : 10.1061/(ASCE)HY.1943-7900.0001109

the hydropower plant turbines, the vicinity of which was first neglected in characterizing the site conditions.

A tentative list of possible metrics for characterizing the conditions of ADCP discharge measurements is proposed in Tab. 5. This list builds on similar discussions (Elizabeth Jamieson, personal communication) during the preparation of the Lethbridge 2014 ADCP interlaboratory experiments (Folk, 2014). The proposed list is certainly not complete nor fully relevant. However, it complements well the (mostly) internal error sources identified by Gonzalez-Castro and Muste (2007), and it helps illustrate the kind of criteria that could be elaborated to classify the measurement conditions of any ADCP gauging. Conversely, this implies that all the necessary parameters for building the metrics should be documented for each interlaboratory experiments, sometimes including additional measurements.

In Tab. 5, the suggested characteristics are related to general, deployment, flow and bed conditions. Some important elements of discharge computation procedures could arguably be added to the list. For instance, keeping the default exponent value $(1 / 6)$ in the vertical velocity profile used for Top/Bottom discharge extrapolation, or adjusting the value with the extrap software for instance (Mueller, 2013) can make a significant difference in some situations. Also, some error sources may be related to a complex combination of different measurements conditions, hence different metrics. For instance, the near-transducer errors due to flow disturbance by the ADCP probe (Mueller et al., 2007; Muste et al., 2010) are related to the size of the ADCP probe and to the apparent velocity relative to it. The magnitude of this effect may therefore be predicted from the type of ADCP, plus the flow and vessel velocities. At the end, the subsequent discharge errors directly depend on ADCP settings such as the cell sizes and the thickness of the unmeasured top layer.

A very practical point regards the sources of information, either the ADCP data or additional information, that could be used to assess the metrics for characterizing the conditions of an ADCP measurement (cf. Tab. 5). A good point is that some useful metrics can be directly derived from the ADCP data themselves: cross-sectional means, some flow field properties, internal and external sensors, bottom-track to GPS differences, etc. 
Author-produced version of the article published in Journal of Hydraulic Engineering-ASCE (2016), vol. 142, $\mathrm{n}^{\circ} 7$ The original publication is available at http://ascelibrary.org/doi/abs/10.1061/\%28ASCE\%29HY.1943-7900.0001109

doi : 10.1061/(ASCE)HY.1943-7900.0001109

However, additional information appears to be necessary, especially about the external conditions, channel properties and deployment techniques. From an operational point of view, simple criteria to be selected in a standardised list must be preferred to additional measurements that could be uselessly taedious or time-consuming for operators. Typically, during ADCP interlaboratory experiments it would be useful to measure velocities in unmeasured subsections with a current-meter, but this is not routinely achievable during ADCP streamgauging operations. Taking pictures or movies of the site, flow and deployment conditions is now costless and often proves to help documenting measurement conditions: free-surface roughness, edge subsections, surface velocities, bed roughness and singularities, flow complexity, quality of the ADCP deployment, etc.

\section{Conclusions and perspectives}

Irrespective of the measurement technique, interlaboratory experiments are a useful tool to assure the quality of hydrometric data. This study demonstrates the applicability of in situ collaborative interlaboratory experiments to quantify the uncertainties of streamgauging techniques under specific site conditions and introduces a standardised procedure for acquiring and processing the results. Several field experiments like the presented example have been conducted to study different streamgauging techniques such as ADCP, surface velocity radars and current-meters mounted on wading-rods or suspended from cables. The introduced method proved to be useful for empirically estimating the final discharge uncertainties. Interlaboratory experiments can provide a useful end-to-end uncertainty analysis approach to characterise a subset of elemental sources of errors acting at the time of the experiments. The covered error sources include site selection, environmental, operator-related and field procedure effects which are highly difficult to predict numerically.

Beyond the costs and difficulties related to their organisation, including the requirements of steady discharge and similar conditions and procedures for all participants, interlaboratory experiments are feasible at many river and canal sites using the proposed method. The results are always affected by statistical limitations. Since the number of 
Author-produced version of the article published in Journal of Hydraulic Engineering-ASCE (2016), vol. 142, $n^{\circ} 7$ The original publication is available at http://ascelibrary.org/doi/abs/10.1061/\%28ASCE\%29HY.1943-7900.0001109

doi : 10.1061/(ASCE)HY.1943-7900.0001109

participants and repeated measurements is limited, samples are usually small and it is not relevant to consider small differences in uncertainty results. The uncertainty of the uncertainty results can be estimated using some simple equations as a function of the numbers of participants and repeated measurements and of the reproducibility-to-repeatability ratio.

A streamflow reference measurement technique with a demonstrated uncertainty that is much lower, typically by one order of magnitude, than that of the studied streamgauging technique is usually missing in field situations. Volumetric or weighing reference techniques used in hydraulic calibration laboratories are not practicable for outdoor hydrometry. Acoustic measurement systems in dam conduits arguably provide the most accurate discharge references in rivers: such systems do not need to be calibrated with gauging data and expanded uncertainties lower than $\pm 2 \%$, typically, have been demonstrated for diameters up to $\sim 1 \mathrm{~m}$; for larger diameters, hydraulic similarity factors may be invoked to extrapolate the traceability to metrological standards. As shown in our application example however, even so uncertainties remain too large for identifying the possible bias of a streamgauging technique like the ADCP.

As a consequence, quantifying the bias of a streamgauging technique, i.e. the systematic error that is common to all participants, is not achievable from the collaborative experiment. Such bias must be estimated from other sources of information such as calibration results or numerical simulation. There are also some limitations due to the large number of sources of error which may significantly contribute to the combined uncertainty. It may then be very difficult, if not impossible, to isolate and quantify the individual effects of each error source using dedicated experiments. Repeating the experiments after permutation of the instruments, operators and/or measuring locations may be a way to discriminate the source of the observed interlaboratory variability.

A promising perspective is to conduct interlaboratory experiments in open-air laboratories, such as the River Experiment Center (http://rec.kict.re.kr/english/, last accessed on 9 June, 2015). in Andong, Korea, which offer the unique opportunity of designing experiments in controlled natural conditions. Typically, environmental influence factors like channel sinuosity, slope, vegetation, sediment transport, etc. could be investigated 
Author-produced version of the article published in Journal of Hydraulic Engineering-ASCE (2016), vol. 142, $n^{\circ} 7$ The original publication is available at http://ascelibrary.org/doi/abs/10.1061/\%28ASCE\%29HY.1943-7900.0001109

doi : 10.1061/(ASCE)HY.1943-7900.0001109

individually under reproducible conditions and with a steady discharge released from a well-calibrated structure. External factors influencing the operators, such as stress, lack of time, weather conditions, etc. could also be investigated.

Collaborative initiatives conducted in natural streams would be very welcome for documenting a wide range of measurement conditions. The uncertainty results would ideally be obtained with the same standardised methodology and populate a world-wide open database. Such uncertainty values can help validate and improve propagation methods and their assumptions on environmental errors. In turn, a GUM-based approach can be used to extend the uncertainty results to measurement conditions other than those of the interlaboratory experiments, especially the most extreme flood conditions. An important issue remains the definition of meaningful metrics and indicators to categorize interlaboratory experiments that could be used by end-users to select the uncertainty results that are representative of their gaugings. We hope that the suggested matrix for ADCP measurements may help the grouping of errors that are assessed.

\section{Acknowledgements}

This research task was supported by the French national hydrological services (SCHAPI). It would not have been possible without the results of several large-scale ADCP, hand-held radars and current-meter interlaboratory experiments organized by the Groupe Doppler Hydrométrie, a working group launched in 2005 by French-speaking hydrometry technologists from different agencies. Our thoughts were enhanced by constructive discussions with the experts of the World Meteorological Organization initiative on the Assessment of the Performance of Flow Measurement Instruments and Techniques. We also thank the two reviewers and the editor for their helpful comments on the manuscript.

\section{Notation}

The following symbols are used in this paper: 
$A_{r}=$ the relative uncertainty half-interval of $s_{r}$ estimate with a probability level of $95 \%$;

$A_{R}=$ the relative uncertainty half-interval of $s_{R}$ estimate with a probability level of $95 \%$;

$B_{i}=$ the systematic (bias) error related to the $i^{\text {th }}$ laboratory;

$c_{i}=$ the sensitivity coefficients related to the effects not covered in the experiments;

$k=$ the coverage factor used to expand the uncertainty to a given probability level;

$n=$ the average number of repeated measurements for each laboratory;

$n_{i}=$ the number of repeated measurements for the $i^{\text {th }}$ laboratory;

$\bar{n}=$ the average number of repeated measurements per laboratory computed using Eq. 5 ;

$N=$ the number of successive ADCP transects averaged to compute a discharge result;

$p=$ the number of participants involved in the interlaboratory experiment;

$P=$ the number of successive ADCP instruments averaged to compute a discharge result;

$Q=$ the discharge;

$Q_{i, k}=$ the $k^{\text {th }}$ instantaneous discharge measurement of the $i^{\text {th }}$ laboratory;

$\bar{Q}_{i}=$ the average of the repeated discharge measurements of the $i^{\text {th }}$ laboratory;

$Q_{\text {mean }}=$ the average of all discharge values of the experiment;

$Q_{\text {ref }}=$ the reference discharge value;

$Q_{\text {true }}=$ the true discharge value (unknown);

$s_{L}=$ the estimator of the interlaboratory standard deviation;

$s_{r}=$ the estimator of the repeatability (intra-laboratory) standard deviation;

$s_{R}=$ the estimator of the reproducibility standard deviation;

$u(X)=$ the relative standard uncertainty associated with the quantity $X$;

$U(X)=$ the expanded relative uncertainty associated with the quantity $X$, with a probability level of $95 \%$;

$x_{i}=$ the input quantities related to the effects not covered in the experiments;

$y=$ the measurement result;

$\gamma=$ the reproducibility to repeatability ratio $\left(\gamma=s_{R} / s r\right)$;

$\delta=$ the bias associated with the measurement technique;

$\hat{\delta}=$ the estimator of the bias of the measurement technique;

$\epsilon_{i, k}=$ the random error related to the $k^{\text {th }}$ discharge measurement of the $i^{\text {th }}$ laboratory; 
$\sigma_{L}=$ the true interlaboratory standard deviation;

$\sigma_{r}=$ the true repeatability (intra-laboratory) standard deviation;

$\sigma_{R}=$ the true reproducibility standard deviation;

\section{References}

COFRAC. Exigences pour l'accréditation des laboratoires selon la norme NF EN ISO/CEI 17025 [Requirements for the accreditation of laboratories according to the NF EN ISO/IEC 17025, in French] LAB REF 02, rev. 9, COFRAC, January 2015, 56 p.

Cohn, T.A., Kiang, J.E., and Mason, R.R. Estimating discharge measurement uncertainty using the interpolated variance estimator. Journal of Hydraulic Engineering, 139(5), $502-510,2013$.

Despax, A., Dramais, G., and Hauet, A. Rapport d'essai : Comparaison de mesures du débit des petits cours d'eau par courantomètres sur perche. Journées d'intercomparaison des 15, 16 et 17 octobre 2013 [Comparison of flow measurements with current meters on wading rods. Intercomparison Days 15, 16 and 17 October 2013. (in French)]. Groupe Doppler Hydrométrie, technical report, 2014, 54 p.

Dramais, G., Blanquart, B., and Le Coz, J. Comparaison de méthodes de mesure du débit des petits cours d'eau. Journées d'intercomparaison des 17 et 18 mai 2011 [Comparison of streamgauging methods for small streams. Intercomparison sessions on May, 17-18, 2011. (in French)]. Irstea, technical report, 2011, 53 p.

Dramais, G., Blanquart, B., Le Coz, J., Pierrefeu, G., Hauet, A., Atmane, D., and Pobanz, K. Les essais interlaboratoires en hydrométrie, méthodologie et cas d'applications [Hydrometric inter-laboratory experiments, procedure and applications (in French)]. $H y$ drométrie2013 SHF conference, 15-16 May 2013, Cachan, France.

Everard, N. ADCP Regatta River Severn at Bewdley 21st August 2007. UK Environment Agency, technical report, 12 p., 2007. 
Author-produced version of the article published in Journal of Hydraulic Engineering-ASCE (2016), vol. 142, $n^{\circ} 7$ The original publication is available at http://ascelibrary.org/doi/abs/10.1061/\%28ASCE\%29HY.1943-7900.0001109 doi : 10.1061/(ASCE)HY.1943-7900.0001109

Everard, N. ADCP Regatta 2009 River Severn at Bewdley 4th June 2009. UK Environment Agency, technical report, 30 p., 2009.

Folk, D. 2013 ADCP Measurement Flotilla. St. Mary's River Irrigation District Main Canal near Lethbridge, Alberta. August 12-13, 2013 Environment Canada - Water Survey of Canada, technical report, 49 p., 2014.

Garcia, C.M., Tarrab, L., Oberg, K., Szupiany, R., and Cantero, M.I. Variance of discharge estimates sampled using ADCPs from moving platforms. Journal of Hydraulic Engineering, 138(8), 684-694, 2012.

Gonzalez-Castro, J.A., and Muste, M. Framework for estimating uncertainty of ADCP measurements from a moving boat by standardized uncertainty analysis. Journal of Hydraulic Engineering, 133(12), 1390-1410, 2007.

Hauet, A., Creutin, J.-D., Belleudy, P., 2008b. Sensitivity study of large-scale particle image velocimetry measurement of river discharge using numerical simulation. Journal of Hydrology 349 (1-2), 178-190.

Hauet, A., Le Coz, J., Sevrez, D., Dramais, G., Hénault, F., Perret, C., Pierrefeu, G., Pobanz, K., and Thollet, F. Intercomparaison ADCP sur le canal de La Gentille (1216/09/2011). [ADCP intercomparison in the Gentille canal (2011/09/12-16). (in French)] Groupe Doppler, technical report, December 2012, 62 p.

Herschy, R.W. The uncertainty in a current meter measurement. Flow Measurement and Instrumentation, 13:281-284, 2002.

Huang, H. Uncertainty model for in situ quality control of stationary ADCP open-channel discharge measurement. Journal of Hydraulic Engineering, 138(1), 4-12, 2012.

IEC 60041 Field acceptance tests to determine the hydraulic performance of hydraulic turbines, storage pumps and pump-turbines. International Electrotechnical Commission, Geneva, Switzerland, 491 p, 1991. 
Author-produced version of the article published in Journal of Hydraulic Engineering-ASCE (2016), vol. 142, $n^{\circ} 7$ The original publication is available at http://ascelibrary.org/doi/abs/10.1061/\%28ASCE\%29HY.1943-7900.0001109

doi : 10.1061/(ASCE)HY.1943-7900.0001109

Iredale, R. A proposed method of assessing the comparative performance of ADCP's. Results from the Environment Agency 'ADCP Regatta', River Severn, Bewdley. ADCPs in Action RDI conference, 2006, Cannes, France.

ISO 5725-1 Accuracy (trueness and precision) of measurement methods and results. Part 1: General principles and definitions. International Organization for Standardization, Geneva, Switzerland, 17 p, 1994.

ISO 5725-2 Accuracy (trueness and precision) of measurement methods and results. Part 2: Basic method for the determination of repeatability and reproducibility of a standard measurement method. International Organization for Standardization, Geneva, Switzerland, 42 p, 1994.

ISO 13528 Statistical methods for use in proficiency testing by interlaboratory comparisons. International Organization for Standardization, Geneva, Switzerland, 66 p, 2005.

ISO/TS 25377 Hydrometric uncertainty guidance (HUG). International Organization for Standardization, Geneva, Switzerland, 51 p, 2007.

ISO 748 Hydrometry - Measurement of liquid flow in open channels using current-meters or floats International Organization for Standardization, Geneva, Switzerland, 46 p, 2007.

ISO 21748 Guidance for the use of repeatability, reproducibility and trueness estimates in measurement uncertainty estimation. International Organization for Standardization, Geneva, Switzerland, 38 p, 2010.

ISO/IEC 17043 Conformity assessment - General requirements for proficiency testing. International Organization for Standardization, Geneva, Switzerland, 39 p, 2010.

JCGM 100:2008 (GUM). Evaluation of measurement data - Guide to the expression of uncertainty in measurement. JCGM member organizations (BIPM, IEC, IFCC, ILAC, ISO, IUPAC, IUPAP and OIML), 120 p, 2008. 
Author-produced version of the article published in Journal of Hydraulic Engineering-ASCE (2016), vol. 142, $n^{\circ} 7$ The original publication is available at http://ascelibrary.org/doi/abs/10.1061/\%28ASCE\%29HY.1943-7900.0001109

doi : 10.1061/(ASCE)HY.1943-7900.0001109

Le Coz, J., Pierrefeu, G., Brochot, J.-F., Saysset, G., and Marchand, P. Jaugeage des rivières par aDcp : pour une culture commune [ADcp river discharge measurement: sharing experience. (in French)] Houille Blanche-Revue Internationale de l'eau, 4:111$118,2007$.

Le Coz, J., Saysset, G., and Pierrefeu, G. Rapport d'essais - Régate ADCP 1, 3-45/02/2009, Vézère au pont de Garavet (Allassac, Corrèze) [Testing report - ADCP Regatta 1, 2009/02/3-4-5, Vézère River at Garavet Bridge, Allassac, France. (in French)]. Groupe Doppler, technical report, October 2009, 33 p.

Le Coz, J., Camenen, B., Peyrard, X., and Dramais, G. Uncertainty in open-channel discharges measured with the velocity-area method. Flow Measurement and Instrumentation, 26:18-29, 2012.

Lee, K., Ho, H.-C., Muste M., and Wua, C.-H. Uncertainty in open channel discharge measurements acquired with StreamPro ADCP. Journal of Hydrology, 509, 101-114, 2014.

McMillan, H., Krueger, T., and Freer, J. Benchmarking observational uncertainties for hydrology: rainfall, river discharge and water quality. Hydrological Processes, 26(26): 4078-4111, 2012.

Mueller, D.S., Abad, J.D., García, C.M., Gartner, J.W., García, M.H., and Oberg, K.A. Errors in acoustic Doppler profiler velocity measurements caused by flow disturbance. Journal of Hydraulic Engineering, 133, 1411-1420, 2007.

Mueller, D.S. extrap: Software to assist the selection of extrapolation methods for movingboat ADCP streamflow measurements. Computers \&6 Geosciences, 54, 211-218, 2013.

Muste, M., Kim, D., Gonzalez-Castro, J.A. Near-transducer errors in ADCP measurements: Experimental findings. Journal of Hydraulic Engineering, 136(5), 275-289, 2010. 
Muste, M., Lee, K., Bertrand-Krajewski, J.-L.. Standardized uncertainty analysis for hydrometry: a review of relevant approaches and implementation examples. Hydrological Sciences Journal, 57(4), 643-667, 2012.

Oberg, K., and Mueller, D.S. Validation of streamflow measurements made with acoustic Doppler current profilers. Journal of Hydraulic Engineering, 133(12), 1421-1432, 2007.

Pelletier, P.M. Uncertainties in the single determination of river discharge: a literature review. Canadian Journal of Civil Engineering, 15:834-850, 1988.

Parsons, D. R., Jackson, P. R., Czuba, J. A., Engel, F. L., Rhoads, B. L., Oberg, K. A., Best, J. L., Mueller, D. S., Johnson, K. K. and Riley, J. D. Velocity Mapping Toolbox (VMT): a processing and visualization suite for moving-vessel ADCP measurements. Earth Surface Processes and Landforms, 38(11):1244-1260, 2013. doi:10.1002/esp.3367.

Pobanz, K., Le Coz, J., and Pierrefeu, G. Intercomparison of ADCPs on the Rhône downstream of Génissiat dam (2010/10/12-15). Groupe Doppler, technical report, 2011, $59 \mathrm{p}$.

Pobanz, K., Le Coz, J., Hauet, A., Thollet, F., Longefay, Y., and Pierrefeu, G. Intercomparaison ADCP/SVR sur le Rhône à l'aval du barrage de Génissiat, 25 au 28 septembre 2012 [ADCP/SVR intercomparison in the Rhône river downstream of Génissiat dam, 2012/09/25-28 (in French)]. Groupe Doppler Hydrométrie, technical report, 2015, in prep.

Terek, T., Bušelić, G., Nimac, N., Bančić, S., Žalac, R., and Lukac I. Interkomparacijsko mjerenje protoka akustičkim Doppler (ADCP) protokomjerima, Sisak, Hrvatska, Rujan 2008 [Intercomparison of flow measurement using acoustic Doppler current profilers (ADCP), Sisak, Croatia, September 2008 (in Croatian)]. DHMZ Zagreb, technical report, 58 p., 2008.

Voser, A., Staubli, T. Integration error of multipath acoustic discharge measurements in 
Author-produced version of the article published in Journal of Hydraulic Engineering-ASCE (2016), vol. 142, $n^{\circ} 7$ The original publication is available at http://ascelibrary.org/doi/abs/10.1061/\%28ASCE\%29HY.1943-7900.0001109 doi : 10.1061/(ASCE)HY.1943-7900.0001109

closed conduits. International Group for Hydraulic Efficiency Measurement, Reno, USA, 15 p., 1998. 


\section{List of Figures}

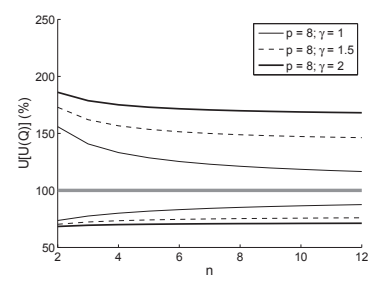

(a)

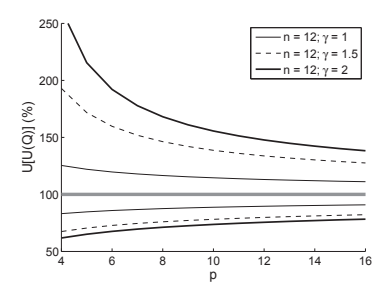

(b)

Figure 1: Uncertainty intervals at a probability level of $95 \%$ around the discharge uncertainty estimate, $U(Q)$, as a function of the number of repeated measurements, $n$ (a), and of laboratories, $p$ (b). The uncertainty bounds were computed using Eq. 13, with $U(Q)=100 \%$ (thick gray line) and $A_{R}$ was computed using Eq. 12 given by ISO 5725-1 (1994). The reproducibility-torepeatability ratio $\left(\gamma=\sigma_{R} / \sigma_{r}\right)$ was varied from 1 to 2 . 
Author-produced version of the article published in Journal of Hydraulic Engineering-ASCE (2016), vol. 142, $n^{\circ} 7$ The original publication is available at http://ascelibrary.org/doi/abs/10.1061/\%28ASCE\%29HY.1943-7900.0001109

doi : 10.1061/(ASCE)HY.1943-7900.0001109
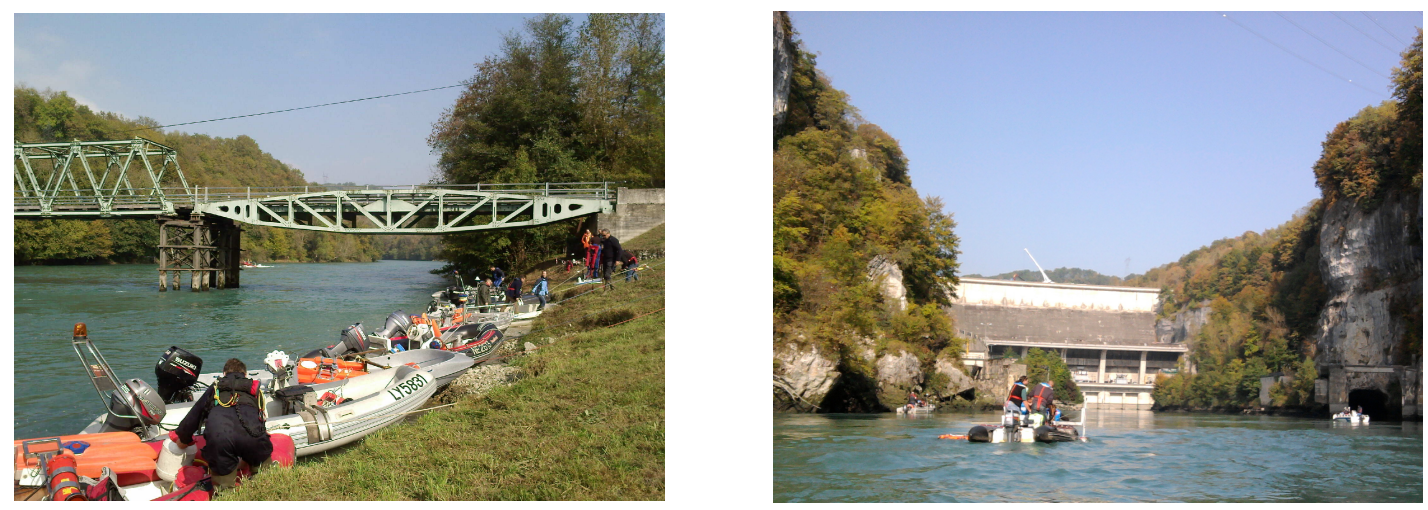

(a)

(b)

Figure 2: Participants of the Génissiat 2010 interlaboratory experiments: boats equipped with ADCP at rest downstream of the Pyrimont bridge (a, photo by J. Le Coz). The reach of PY site is visible upstream of the bridge. Measurements being conducted at GE site, downstream of Génissiat hydropower plant (b, photo by G. Pierrefeu). 
Author-produced version of the article published in Journal of Hydraulic Engineering-ASCE (2016), vol. 142, $n^{\circ} 7$ The original publication is available at http://ascelibrary.org/doi/abs/10.1061/\%28ASCE\%29HY.1943-7900.0001109 doi : 10.1061/(ASCE)HY.1943-7900.0001109
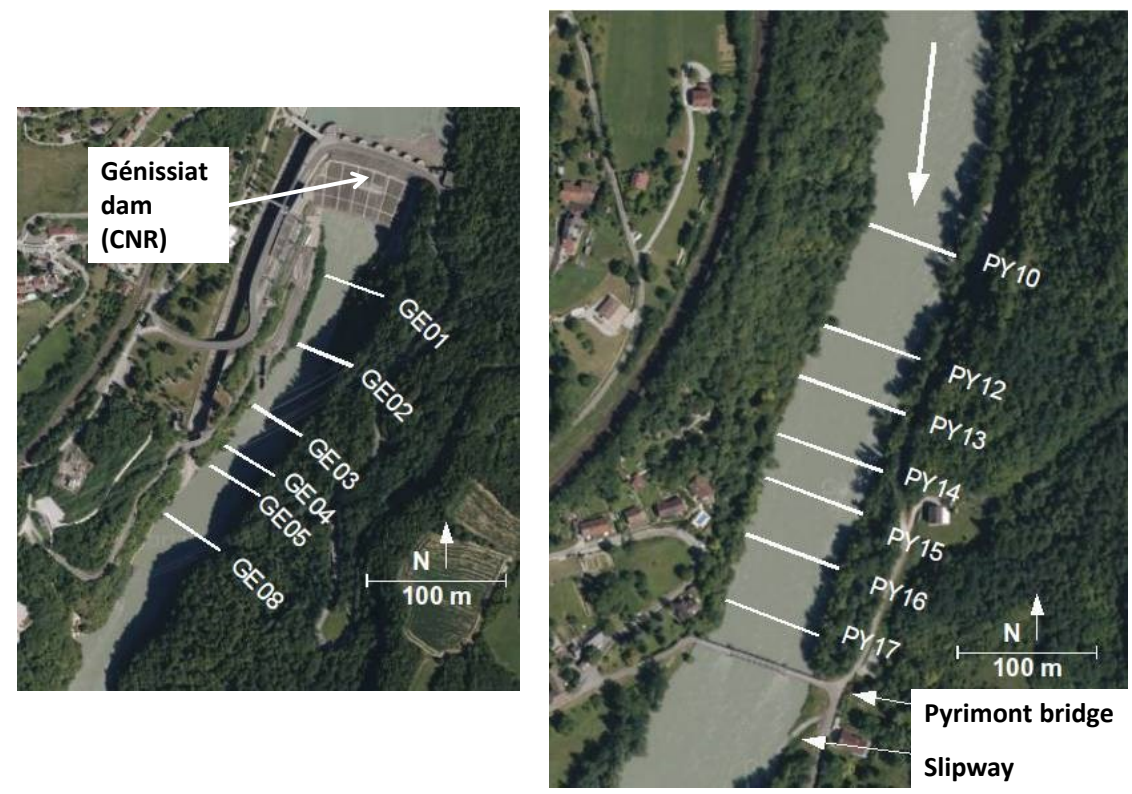

(a)

(b)

Figure 3: Aerial view of the ADCP transects at both sites of the Génissiat 2010 interlaboratory experiments: GE site downstream of the hydropower plant (a) and PY site upstream of the Pyrimont bridge (b). Modified from Google Maps (Map data (C) 2010 Google). 

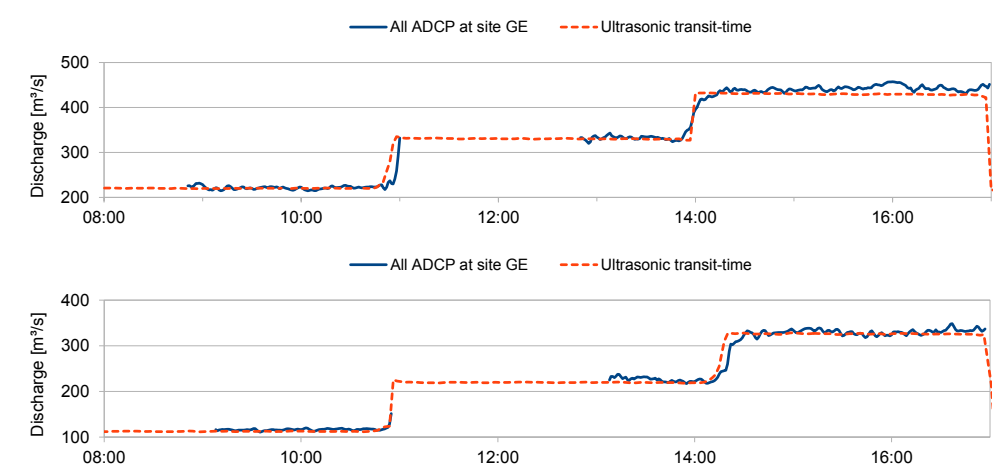

(a)
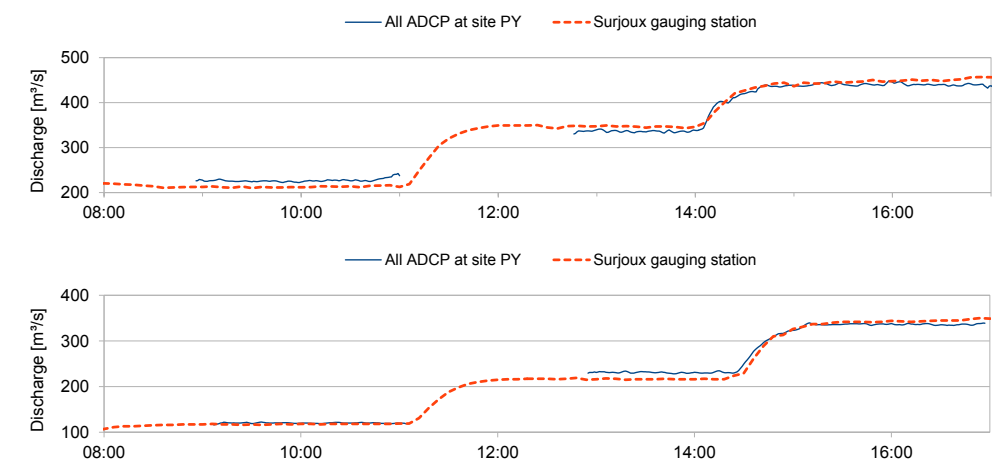

(b)

Figure 4: Controlled discharge hydrograph during the Génissiat 2010 interlaboratory experiments: average discharge time series measured by all ADCP at sites GE (a) and PY (b). Data for 2010/10/13 and 2010/10/14 are shown on top and bottom of the figures, respectively. Reference discharges are computed from the ultrasonic transit-time system in the dam conduits (GE site, a) while the discharges from the rating curve of Surjoux hydrometric station (PY site, b) are provided for illustration only. 
Author-produced version of the article published in Journal of Hydraulic Engineering-ASCE (2016), vol. 142, $n^{\circ} 7$ The original publication is available at http://ascelibrary.org/doi/abs/10.1061/\%28ASCE\%29HY.1943-7900.0001109

\section{0/10/13 - Experiment S2b}

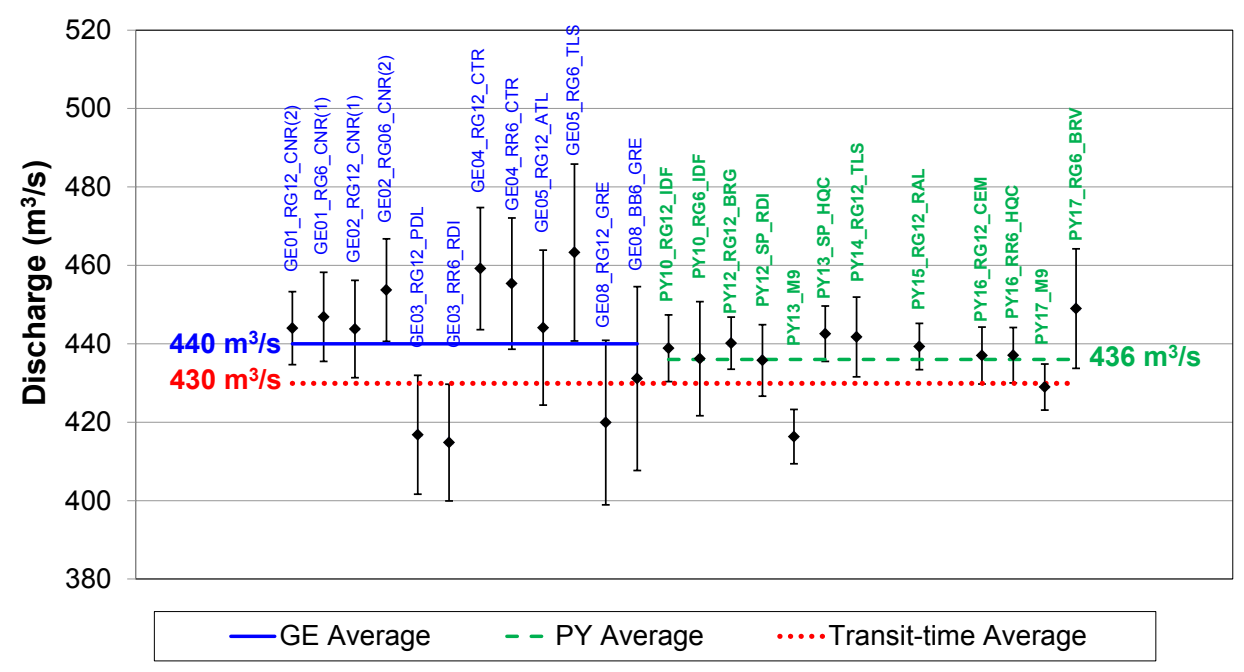

Figure 5: Example of discharge results obtained during one steady-discharge experiment during the Génissiat 2010 ADCP interlaboratory experiments (2010/10/13, experiment S2b). Dots and error bars stand for the discharge average and \pm 1 standard-deviation, respectively, for every participants. Discharge averages over all ADCPs at sites GE and PY, and from transit-time system in dam conduits are shown as solid, dashed and dotted horizontal segments, respectively. 
Author-produced version of the article published in Journal of Hydraulic Engineering-ASCE (2016), vol. 142, $\mathrm{n}^{\circ} 7$ The original publication is available at http://ascelibrary.org/doi/abs/10.1061/\%28ASCE\%29HY.1943-7900.0001109

doi : 10.1061/(ASCE)HY.1943-7900.0001109

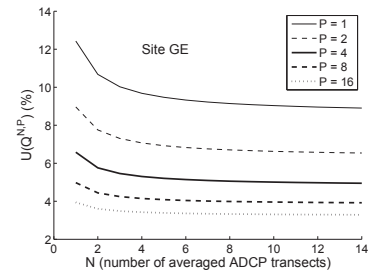

(a)

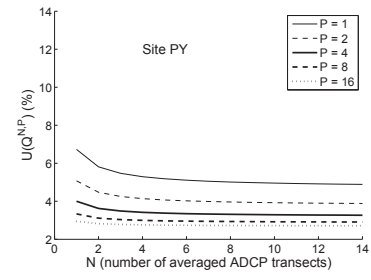

(b)

Figure 6: Expanded uncertainty in discharges measured as the average of $N$ transects from $P$ ADCP at both sites of the Génissiat 2010 interlaboratory experiments: GE site with adverse conditions (a) and PY site with favourable conditions (b). Expanded uncertainties are expressed with a probability level of $95 \%$. 
Author-produced version of the article published in Journal of Hydraulic Engineering-ASCE (2016), vol. 142, $n^{\circ} 7$

The original publication is available at http://ascelibrary.org/doi/abs/10.1061/\%28ASCE\%29HY.1943-7900.0001109

doi : 10.1061/(ASCE)HY.1943-7900.0001109
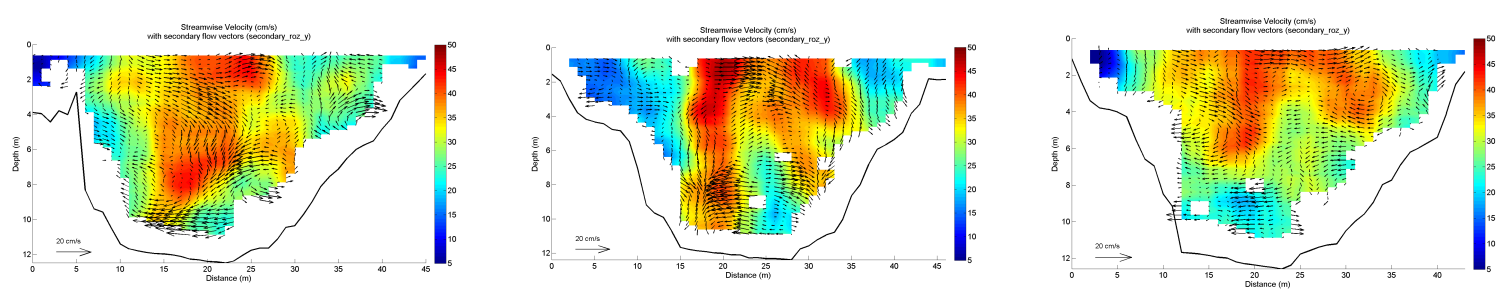

(a)
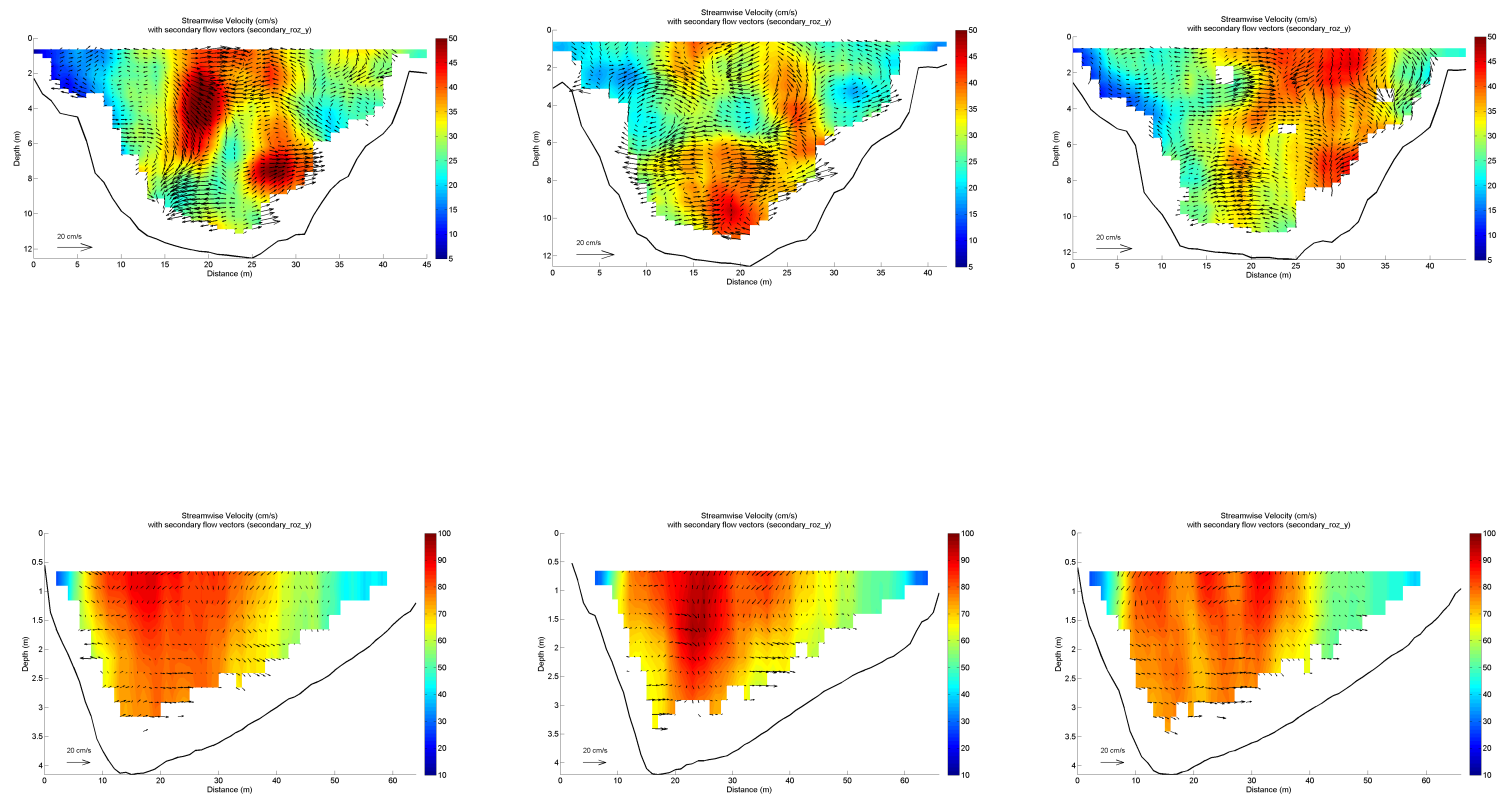

(b)
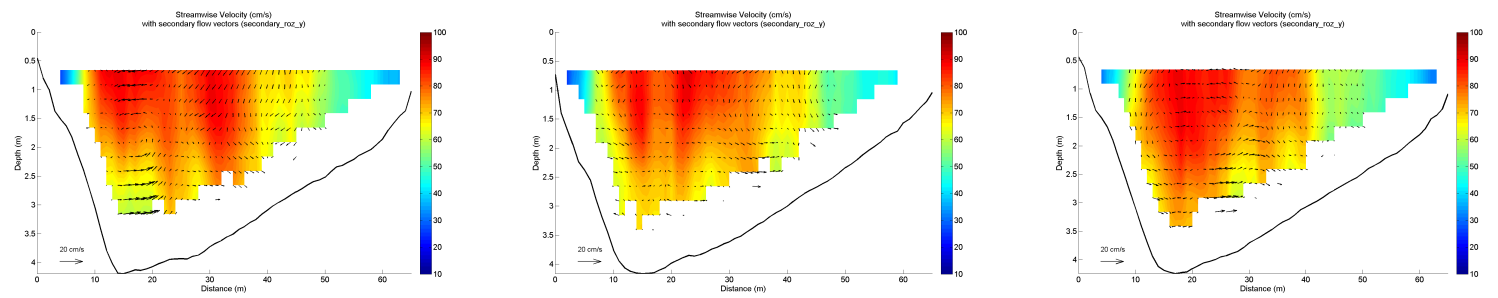

Figure 7: Six successive ADCP transects from the Génissiat 2010 interlaboratory experiments at GE (a) and PY (b) sites. ADCP data were processed with the VMT software (Parsons et al., 2013) to plot the measured bottom profile (white line), the streamwise velocity magnitude (contours) and the secondary velocity field (black vectors). Intermittent macroturbulent structures are identified in the ADCP transects measured at GE site, downstream of the hydropower plant turbine outlets. Secondary currents and flow pulsations were much less intense at PY site, where the flow structure was much more stable. 
Author-produced version of the article published in Journal of Hydraulic Engineering-ASCE (2016), vol. 142, $n^{\circ} 7$ The original publication is available at http://ascelibrary.org/doi/abs/10.1061/\%28ASCE\%29HY.1943-7900.0001109 doi : 10.1061/(ASCE)HY.1943-7900.0001109

\section{Steps To-do list}

Preparation Select a site and determine its main characteristics

Assess hydro-meteorological conditions (forecast, hydropower...)

Prepare and share a description of the experiments and their objectives

Prepare and share a risk assessment plan

Prepare and share accommodation and logistical solutions

List the participants and their contacts (e-mails, cell phone numbers)

Set-up Prepare the site and install all the necessary equipment

Mark the measurement locations for all the participants

Brief and de-brief the participants on the objectives, schedule, weather

and hydrological situation, safety rules, etc., and get their feedback

Distribute field forms and remind imposed file names and settings

Provide each participant with a memory stick identified with a code

Execution Assure permanent communication between leaders and participants

Synchronise all clocks, instruments and computers within 5 seconds

Strictly coordinate the deployment of instruments as planned

Observe a warm-up session before starting the experiments

Launch and stop time slots rather than impose parallel gaugings

Collect raw and validated data with photos and movies after each run

Compilation Ask each participant to review their measurements after each session Display the results of every laboratory on a paper board: mean discharges, standard-deviations, numbers of valid measurements, etc.

Process the interlaboratory results in situ, using a dedicated spreadsheet

Back in the office, review all the discharge and ancillary data

Establish the final uncertainty results and report

Proceed with data archival and reporting using a standardised format

Table 1: Main practical steps for organizing interlaboratory experiments to document the uncertainty of streamgauging techniques. 
Author-produced version of the article published in Journal of Hydraulic Engineering-ASCE (2016), vol. 142, $n^{\circ} 7$ The original publication is available at http://ascelibrary.org/doi/abs/10.1061/\%28ASCE\%29HY.1943-7900.0001109

doi : 10.1061/(ASCE)HY.1943-7900.0001109

\begin{tabular}{cccc}
\hline Model & $\begin{array}{c}\text { Frequency } \\
\mathrm{kHz}\end{array}$ & Brand & Number \\
& 600 & Teledyne RDI & 1 \\
BroadBand & 600 & Teledyne RDI & 6 \\
RioGrande & 600 & Teledyne RDI & 3 \\
RiverRay & 1200 & Teledyne RDI & 11 \\
RioGrande & $1000 / 3000$ & SonTek & 2 \\
M9 & 2400 & Teledyne RDI & 3 \\
\hline
\end{tabular}

Table 2: Types of the 25 ADCP deployed during the Génissiat 2010 interlaboratory experiments. Note: the M9 used a separate vertical beam for depth sounding, with a $500 \mathrm{kHz}$ frequency. 
Author-produced version of the article published in Journal of Hydraulic Engineering-ASCE (2016), vol. 142, $n^{\circ} 7$ The original publication is available at http://ascelibrary.org/doi/abs/10.1061/\%28ASCE\%29HY.1943-7900.0001109 doi : 10.1061/(ASCE)HY.1943-7900.0001109

\begin{tabular}{|c|c|c|c|c|c|c|c|c|}
\hline \multirow[b]{2}{*}{ Variables } & \multirow[b]{2}{*}{ Units/Source } & \multicolumn{6}{|c|}{ Experiments } & \multirow[b]{2}{*}{ Average } \\
\hline & & S1 & S2 & $\mathbf{S} 2 \mathrm{~b}$ & S3 & $\mathrm{S} 4$ & $\mathrm{~S} 4 \mathrm{~b}$ & \\
\hline $\mathbf{p}$ & (participants) & 13 & 13 & 12 & 14 & 14 & 12 & 13 \\
\hline$\overline{\mathbf{n}}$ & (transects) & 19.6 & 15.0 & 24.2 & 17.9 & 13.9 & 18.2 & 18.1 \\
\hline $\mathbf{Q}_{\text {mean }}$ & $\left(\mathrm{m}^{3} / \mathrm{s}\right)$ & 224 & 335 & 436 & 120 & 230 & 335 & - \\
\hline $\mathrm{Q}_{\mathrm{ref}}$ & $\left(\mathrm{m}^{3} / \mathrm{s}\right)$ & 218 & 328 & 430 & 118 & 227 & 333 & - \\
\hline$\hat{\delta}$ & (Eq. 8) & $+2.6 \%$ & $+2.3 \%$ & $+1.5 \%$ & $+1.3 \%$ & $+1.4 \%$ & $+0.6 \%$ & $+1.6 \%$ \\
\hline $\mathrm{sr}_{\mathrm{r}}$ & (Eq. 4) & $2.1 \%$ & $2.9 \%$ & $2.1 \%$ & $2.6 \%$ & $2.8 \%$ & $1.9 \%$ & $2.4 \%$ \\
\hline $\mathbf{s}_{\mathbf{L}}$ & (Eq. 5) & $2.2 \%$ & $2.0 \%$ & $1.8 \%$ & $1.8 \%$ & $2.3 \%$ & $1.8 \%$ & $2.0 \%$ \\
\hline $\mathbf{s}_{\mathbf{R}}$ & (Eq. 6) & $3.0 \%$ & $3.5 \%$ & $2.8 \%$ & $3.1 \%$ & $3.6 \%$ & $2.7 \%$ & $3.1 \%$ \\
\hline$\gamma$ & $\left(s_{R} / s_{r}\right)$ & 1.5 & 1.2 & 1.3 & 1.2 & 1.3 & 1.4 & 1.3 \\
\hline $\mathbf{A}_{\mathbf{r}}$ & (Eq. 11) & $9 \%$ & $10 \%$ & $8 \%$ & $9 \%$ & $10 \%$ & $10 \%$ & $9 \%$ \\
\hline $\mathbf{A}_{\mathbf{R}}$ & (Eq.12) & $22 \%$ & $16 \%$ & $20 \%$ & $15 \%$ & $18 \%$ & $21 \%$ & $19 \%$ \\
\hline $\mathbf{1} /\left(\mathbf{1}+\mathbf{A}_{\mathbf{R}}\right)$ & (Eq.13) & $82 \%$ & $86 \%$ & $83 \%$ & $87 \%$ & $85 \%$ & $82 \%$ & $84 \%$ \\
\hline $\mathbf{1} /\left(\mathbf{1}-\mathbf{A}_{\mathbf{R}}\right)$ & (Eq.13) & $129 \%$ & $119 \%$ & $125 \%$ & $118 \%$ & $122 \%$ & $127 \%$ & $123 \%$ \\
\hline $\mathbf{u}\left(\mathbf{Q}_{\mathrm{ref}}\right)$ & (estim.) & $1.0 \%$ & $1.0 \%$ & $1.0 \%$ & $1.0 \%$ & $1.0 \%$ & $1.0 \%$ & $1.0 \%$ \\
\hline $\mathbf{u}\left(\mathbf{Q}_{\text {mean }}\right)$ & (Eq. 10) & $0.6 \%$ & $0.6 \%$ & $0.5 \%$ & $0.5 \%$ & $0.6 \%$ & $0.5 \%$ & $0.6 \%$ \\
\hline $\mathbf{u}(\hat{\delta})$ & (Eq. 10) & $1.2 \%$ & $1.2 \%$ & $1.1 \%$ & $1.1 \%$ & $1.2 \%$ & $1.1 \%$ & $1.2 \%$ \\
\hline $\mathbf{u}(\hat{\delta})$ & (estim.) & $1.25 \%$ & $1.25 \%$ & $1.25 \%$ & $1.25 \%$ & $1.25 \%$ & $1.25 \%$ & $1.25 \%$ \\
\hline $\mathbf{U}\left(\mathbf{Q}^{\mathbf{1}, \mathbf{1}}\right)$ & (Eq. 14) & $\pm 6.6 \%$ & $\pm 7.5 \%$ & $\pm 6.1 \%$ & $\pm 6.8 \%$ & $\pm 7.6 \%$ & $\pm 5.9 \%$ & $\pm \mathbf{6 . 7} \%$ \\
\hline $\mathbf{U}\left(\mathbf{Q}^{\mathbf{4 , 1}}\right)$ & (Eq. 14) & $\pm 5.5 \%$ & $\pm 5.5 \%$ & $\pm 4.9 \%$ & $\pm 5.1 \%$ & $\pm 5.9 \%$ & $\pm 4.8 \%$ & $\pm \mathbf{5 . 3} \%$ \\
\hline $\mathbf{U}\left(\mathbf{Q}^{\mathbf{6 , 1}}\right)$ & (Eq. 14) & $\pm 5.3 \%$ & $\pm 5.3 \%$ & $\pm 4.8 \%$ & $\pm 4.9 \%$ & $\pm 5.7 \%$ & $\pm 4.7 \%$ & $\pm \mathbf{5 . 1} \%$ \\
\hline
\end{tabular}

Table 3: Results of the 6 interlaboratory experiments conducted at PY site of Génissiat 2010. Expanded uncertainties, $U$, are expressed with a probability level of $95 \%$. 
Author-produced version of the article published in Journal of Hydraulic Engineering-ASCE (2016), vol. 142, $n^{\circ} 7$ The original publication is available at http://ascelibrary.org/doi/abs/10.1061/\%28ASCE\%29HY.1943-7900.0001109

doi : 10.1061/(ASCE)HY.1943-7900.0001109

\begin{tabular}{|c|c|c|c|c|c|c|c|c|}
\hline \multirow[b]{2}{*}{ Variables } & \multirow[b]{2}{*}{ Units/Source } & \multicolumn{6}{|c|}{ Experiments } & \multirow[b]{2}{*}{ Average } \\
\hline & & S1 & $\mathrm{S} 2$ & $\mathrm{~S} 2 \mathrm{~b}$ & S3 & $\mathrm{S} 4$ & $\mathrm{~S} 4 \mathrm{~b}$ & \\
\hline $\mathbf{p}$ & (participants) & 12 & 12 & 12 & 12 & 10 & 11 & 12 \\
\hline$\overline{\mathbf{n}}$ & (transects) & 37.1 & 18.7 & 37.1 & 30.5 & 16.9 & 29.5 & 28.3 \\
\hline $\mathbf{Q}_{\text {mean }}$ & $\left(\mathrm{m}^{3} / \mathrm{s}\right)$ & 222 & 336 & 440 & 116 & 226 & 331 & - \\
\hline $\mathbf{Q}_{\mathrm{ref}}$ & $\left(\mathrm{m}^{3} / \mathrm{s}\right)$ & 218 & 328 & 430 & 118 & 227 & 333 & - \\
\hline$\hat{\delta}$ & (Eq. 8) & $+1.9 \%$ & $+2.3 \%$ & $+2.4 \%$ & $-1.7 \%$ & $-0.3 \%$ & $-0.5 \%$ & $+0.7 \%$ \\
\hline $\mathbf{s}_{\mathbf{r}}$ & (Eq. 4) & $4.1 \%$ & $4.4 \%$ & $3.6 \%$ & $5.4 \%$ & $4.5 \%$ & $4.9 \%$ & $4.5 \%$ \\
\hline $\mathbf{s}_{\mathbf{L}}$ & (Eq. 5) & $3.5 \%$ & $3.8 \%$ & $3.8 \%$ & $5.3 \%$ & $4.3 \%$ & $3.9 \%$ & $4.1 \%$ \\
\hline $\mathbf{s}_{\mathbf{R}}$ & (Eq. 6) & $5.4 \%$ & $5.9 \%$ & $5.2 \%$ & $7.6 \%$ & $6.2 \%$ & $6.2 \%$ & $6.1 \%$ \\
\hline$\gamma$ & $\left(s_{R} / s_{r}\right)$ & 1.3 & 1.3 & 1.4 & 1.4 & 1.4 & 1.3 & 1.4 \\
\hline $\mathbf{A}_{\mathbf{r}}$ & (Eq. 11) & $7 \%$ & $9 \%$ & $7 \%$ & $7 \%$ & $11 \%$ & $8 \%$ & $8 \%$ \\
\hline $\mathbf{A}_{\mathbf{R}}$ & (Eq.12) & $19 \%$ & $20 \%$ & $22 \%$ & $22 \%$ & $24 \%$ & $19 \%$ & $21 \%$ \\
\hline $\mathbf{1} /\left(\mathbf{1}+\mathbf{A}_{\mathbf{R}}\right)$ & (Eq.13) & $84 \%$ & $83 \%$ & $82 \%$ & $82 \%$ & $81 \%$ & $84 \%$ & $83 \%$ \\
\hline $\mathbf{1} /\left(\mathbf{1}-\mathbf{A}_{\mathbf{R}}\right)$ & (Eq.13) & $123 \%$ & $125 \%$ & $129 \%$ & $128 \%$ & $132 \%$ & $123 \%$ & $126 \%$ \\
\hline $\mathbf{u}\left(\mathbf{Q}_{\mathrm{ref}}\right)$ & (estim.) & $1.0 \%$ & $1.0 \%$ & $1.0 \%$ & $1.0 \%$ & $1.0 \%$ & $1.0 \%$ & $1.0 \%$ \\
\hline $\mathbf{u}\left(\mathbf{Q}_{\text {mean }}\right)$ & (Eq. 10) & $1.0 \%$ & $1.1 \%$ & $1.1 \%$ & $1.6 \%$ & $1.4 \%$ & $1.2 \%$ & $1.2 \%$ \\
\hline $\mathbf{u}(\hat{\delta})$ & (Eq. 10) & $1.4 \%$ & $1.5 \%$ & $1.5 \%$ & $1.9 \%$ & $1.7 \%$ & $1.6 \%$ & $1.6 \%$ \\
\hline $\mathbf{u}(\hat{\delta})$ & (estim.) & $1.25 \%$ & $1.25 \%$ & $1.25 \%$ & $1.25 \%$ & $1.25 \%$ & $1.25 \%$ & $1.25 \%$ \\
\hline $\mathbf{U}\left(\mathbf{Q}^{\mathbf{1}, \mathbf{1}}\right)$ & (Eq. 14) & $\pm 11.0 \%$ & $\pm 12.0 \%$ & $\pm 10.7 \%$ & $\pm 15.3 \%$ & $\pm 12.7 \%$ & $\pm 12.7 \%$ & $\pm \mathbf{1 2 . 4} \%$ \\
\hline $\mathbf{U}\left(\mathbf{Q}^{\mathbf{4 , 1}}\right)$ & (Eq. 14) & $\pm 8.5 \%$ & $\pm 9.2 \%$ & $\pm 8.7 \%$ & $\pm 12.2 \%$ & $\pm 10.0 \%$ & $\pm 9.5 \%$ & $\pm \mathbf{9 . 7} \%$ \\
\hline $\mathbf{U}\left(\mathbf{Q}^{\mathbf{6}, \mathbf{1}}\right)$ & (Eq. 14) & $\pm 8.1 \%$ & $\pm 8.8 \%$ & $\pm 8.4 \%$ & $\pm 11.8 \%$ & $\pm 9.7 \%$ & $\pm 9.1 \%$ & $\pm \mathbf{9 . 3} \%$ \\
\hline
\end{tabular}

Table 4: Results of the 6 interlaboratory experiments conducted at GE site of Génissiat 2010. Expanded uncertainties, $U$, are expressed with a probability level of $95 \%$. 


\begin{tabular}{|c|c|c|c|c|}
\hline Error Types & Characteristics & Related ADCP error sources & Possible metrics & Information sources \\
\hline \multirow[t]{6}{*}{ Environment } & Cross-sectional means & Flow and geometry errors & Mean velocity, depth, width & $\mathrm{ADCP}$ \\
\hline & Cross-section shape & Flow and geometry errors & Asymmetry, multiple threads & $\mathrm{ADCP} /$ user \\
\hline & Channel sinuosity & Discharge extrapolation & Curvature, sinuosity ratio & user \\
\hline & Weather conditions & Flow errors, deployment & Wind, rain, storm & user \\
\hline & Free-surface conditions & Projection errors, oscillations, etc. & Waves amplitude & user \\
\hline & Water properties & Signal-to-noise ratio, sound celerity & Temperature, turbidity & $\mathrm{ADCP} /$ user \\
\hline \multirow[t]{4}{*}{ Instrument } & Type of ADCP & Intrusion, Doppler noise & Make, frequency & $\mathrm{ADCP}$ \\
\hline & Type of mount & Projection errors, oscillations, etc. & Mount/platform type & user/ADCP \\
\hline & Depth sounding & Depth errors & $\mathrm{ADCP} /$ external sounder & $\mathrm{ADCP}$ \\
\hline & Positioning reference & Positioning and projection errors & None/BT/GPS & $\mathrm{ADCP}$ \\
\hline \multirow[t]{4}{*}{ Deployment } & Trajectory & Projection errors, time-average & Rotation, acceleration & $\mathrm{ADCP}$ \\
\hline & Draft measurement & Top discharge estimate & Eye/Rule/Known & user \\
\hline & Edge distance measurement & Edge discharge estimate & Eye/Rule/Laser & user \\
\hline & Time of exposure & Time-averaging errors & Duration, number of transects & $\mathrm{ADCP}$ \\
\hline \multirow[t]{5}{*}{ Flow } & Longitudinal uniformity & Top/Bottom discharge estimates & Water slope, backwater & user \\
\hline & Discharge unsteadiness & Time-averaging errors & Stage changes & $\mathrm{ADCP} /$ user \\
\hline & Flow instability & Projection/time-averaging errors & Turbulence, velocities, $\ldots$ & $\mathrm{ADCP} /$ user \\
\hline & Flow inhomogeneity & Projection errors & Turbulence, error velocity, angles & $\mathrm{ADCP} /$ user \\
\hline & Near-edge flows & Edge discharge estimate & Near-edge velocity profile & user \\
\hline \multirow[t]{5}{*}{ Bed } & Bed roughness & Bottom/top discharge estimates & Bed material nature/size & user \\
\hline & Bed vegetation & Bottom-tracking and depth errors & Vegetation nature/size & user \\
\hline & Bed singularities & Bottom-tracking and depth errors & Bedforms, obstacles... & user \\
\hline & Edge shape and size & Edge discharge estimate & Edge distance and depth & $\mathrm{ADCP}$ \\
\hline & Bedload transport & Moving bed correction & Active/BT drift & user/ADCP \\
\hline
\end{tabular}

Table 5: Characteristics of ADCP measurements that could be related to error sources and would possibly be meaningful for categorizing ADCP interlaboratory experiments (not exhaustive, provided for discussion). BT stands for bottom-tracking. 